Opinion In Chemical Biology

Elsevier Editorial system(tm) for Current

Manuscript Draft

Manuscript Number: COCHBI-D-15-00058R1

Title: Synthetic biology for microbial production of lipid-based biofuels

Article Type: SI: 29 Energy (2015)

Corresponding Author: Prof. Jay Keasling,

Corresponding Author's Institution: University of California, Berkeley

First Author: Leo d'Espaux, Ph.D.

Order of Authors: Leo d'Espaux, Ph.D.; Daniel Mendez-Perez, Ph.D.; Rachel Li; Jay Keasling

Abstract: The risks of maintaining current $\mathrm{CO} 2$ emission trends have led to interest in producing biofuels using engineered microbes. Microbial biofuels reduce emissions because $\mathrm{CO} 2$ produced by fuel combustion is offset by $\mathrm{CO} 2$ captured by growing biomass, which is later used as feedstock for biofuel fermentation. Hydrocarbons found in petroleum fuels share striking similarity with biological lipids. Here we review synthetic metabolic pathways based on fatty acid and isoprenoid metabolism to produce alkanes and other molecules suitable as biofuels. We further discuss engineering strategies to optimize engineered biosynthetic routes, as well as the potential of synthetic biology for sustainable manufacturing. 
Dear Editor and Reviewers,

Please find below responses to reviewer's comments, and later highlighted changes between the original and the resubmitted drafts.

Best,

Leo

Reviewers' comments:

Reviewer \#1: The review paper is well-written. However, it did not have both page and line numbers so that it was difficult to review the manuscript. The authors summarized recent progress in microbial engineering efforts for producing advanced biofuels.

>>> Thank you for your comments. Page numbers have been added.

These are suggested minor changes:

- As the manuscript focused on advanced biofuels, the title can be changed into "Synthetic biology for microbial production of advanced biofuels"

>> We have changed the title to "Synthetic biology for microbial production of lipid-based biofuels"

- All highlighted reference will need one sentence summary.

>> Summaries are provided in the "Highlights" section at the beginning of the pdf

- Redundant paragraphs, the following two paragraph are too similar:

(omitted)

>>>Apologies for this oversight, which has been corrected.

- A well-known and genetically tractable host, such as Escherichia coli or Saccharomyces cerevisiae, can be engineered TO convert a simple feedstock

>> This sentence has been changed. 
Reviewer \#2: The authors have provide a succinct-yet-thorough review of microbial biosynthesis of lipid-derived fuel molecules. The manuscript will undoubtedly provide a valuable resource for the biofuels community. I recommend the following minor revisions to strengthen the manuscript and enhance its value to the scientific community:

1. The subject material is primarily focused on classical metabolic engineering strategies ("pushpull-block"). There is an array of novel synbio tools currently being leveraged for microbial engineering that is overlooked here (such as functional optimization of gene clusters/synthetic gene networks, logic circuits, design-build-test strategies, in vivo editing, etc). The authors mention these in passing in the Conclusions section, but the manuscript would be strengthened significantly through addition of a short section focused on application of these tools for microbial biosynthesis of fuel molecules. Additionally, there are an array of non-lipid-derived fuel molecules and precursors currently under examination by the biofuels community (e.g. higher alcohols). These certainly fall outside the scope of this review, but it may be more accurate to entitle this work "Metabolic Engineering Strategies Targeting Lipid Biofuels" to more accurately reflect the subject matter.

>> We appreciate these thoughtful suggestions. We have changed the title to "Synthetic biology for microbial production of lipid-based biofuels" to reflect our scope. We have also added and consolidated material into a section on next-generation synthetic biology tools.

2. The paragraph starting with "Alkanes and alkenes - the major constituents of petroleum diesel" - appears in the manuscript twice.

\section{>> Apologies, we have removed the second copy.}

3. If available, the productivity ( $\mathrm{g} / \mathrm{l} / \mathrm{hr}$ ) associated with the lipid fuels in Table 1 would be a nice addition.

>> Unfortunately, this information is not provided in most referenced reports.

4. Related to point 3 above, a brief discussion of the technoeconomic state of technology for the molecules in Table 1 would be welcome. For example, is a $7 \mathrm{~g} / \mathrm{L}$ titer at $28 \%$ yield for FFA technoeconomically viable? If not, how far from viability and how can synbio address the 
limitations? A single sentence or two commenting on this would suffice to orient the reader within the context of real-world deployment.

>> We felt that a thorough discussion would need to include considerations such as subsidies (both to biofuel and petrofuel producers, as well as to farmers, etc.) which would not fit due to space constraints. However we have added some thoughts on the viability of bioprocesses in relation to feedstock costs and other factors in the conclusion section.

5. General: overall, the manuscript reads as more of a review than a "current opinion." Space permitting, the authors are encouraged to explicitly share their opinion on the best path forward for synbio-guided biofuels.

>> We have significantly changed several parts of the manuscript to allow for greater commentary and prognostication.

6. Final paragraph has minor grammatical issues that need to be addressed.

>> We have changed the final section and removed much of the problematic language. 


\section{Highlights}

- Biological lipids are naturally energy-dense and several make good biofuels.

- Metabolic pathways to produce these biofuels have been engineered in microbial hosts.

- A wide range of tools and methodologies are available for improving biofuel production.

- Synthetic biology offers great potential for sustainable manufacturing.

\section{Reference Highlights}

** Choi YJ, Lee SY. 2013. Microbial production of short-chain alkanes. Nature 502:571-4.

This paper shows production of short chain hydrocarbons for the first time using a fatty acyl-CoA reductase from Clostridium acetobutylicum and a fatty aldehyde decarbonylase from Arabidopsis thaliana.

** Haushalter RW, Groff D, Deutsch S, The L, Chavkin T a., Brunner SF, Katz L, Keasling JD. 2015. Fatty acid synthase produces acyl thioester intermediates as acyl-CoADevelopment of an orthogonal fatty acid biosynthesis system in E. coli for oleochemical production. Metab Eng $30: 1-6$.

Type I fatty acid synthases were expressed for the first time in parallel with native E. coli fatty acid synthase for the production of fatty alcohols and methyl ketones.

**Liu Q, Wu K, Cheng Y, Lu L, Xiao E, Zhang Y, Deng Z, Liu T. 2015. Engineering an iterative polyketide pathway in Escherichia coli results in single-form alkene and alkane overproduction. Metab Eng 28:82-90.

An iterative polyketide pathway was engineered for the production of alkenes.

*Alonso-Gutierrez J, Kim E-M, Batth TS, Cho N, Hu Q, Chan LJG, Petzold CJ, Hillson NJ, Adams PD, Keasling JD, Garcia-Martin H, Soon Lee T. 2014. Principal component analysis of proteomics (PCAP) as a tool to direct metabolic engineering. Metab Eng 28:123-133.

* Leber C, Polson B, Fernandez-Moya R, Da Silva N a. 2015. Overproduction and secretion of free fatty acids through disrupted neutral lipid recycle in Saccharomyces cerevisiae. Metab Eng 28:54-62.

* Shi S, Chen Y, Siewers V: Improving Production of Malonyl Coenzyme A-Derived Metabolites. MBio 2014, doi:10.1128/mBio.01130-14.Editor. 
* Kozak BU, van Rossum HM, Luttik MAH, Akeroyd M, Benjamin KR, Wu L, de Vries S, Daran J-M, Pronk JT, van Maris AJA: Engineering acetyl coenzyme A supply: functional expression of a bacterial pyruvate dehydrogenase complex in the cytosol of Saccharomyces cerevisiae. [Internet]. MBio 2014, 5:e01696-14.

**Chowdhury A, Zomorrodi AR, Maranas CD: k-OptForce: integrating kinetics with flux balance analysis for strain design. [Internet]. PLoS Comput. Biol. 2014, 10:e1003487.

A whole-genome scale computational model including flux balance analysis and kinetic data is used to predict beneficial strain improvements

** DiCarlo JE, Norville JE, Mali P, Rios X, Aach J, Church GM: Genome engineering in Saccharomyces cerevisiae using CRISPR-Cas systems. [Internet]. Nucleic Acids Res. 2013, 41:4336-43.

Cas9-mediated gene editing is demonstrated for the first time in S. cerevisiae. 


\title{
Synthetic biology for microbial production of lipid-based biofuels
}

Leo d'Espaux ${ }^{1}$, Daniel Mendez-Perez ${ }^{1}$, Rachel $\mathrm{Li}^{1,2}$, and Jay D. Keasling ${ }^{1,2,3}$

\author{
Author Affiliations \\ ${ }^{1}$ Joint BioEnergy Institute, Lawrence Berkeley National Laboratory, Emeryville, California \\ 94608 \\ ${ }^{2}$ Department of Plant and Microbial Biology, University of California, Berkeley, California \\ 94270 \\ ${ }^{3}$ QB3 Institute, Departments of Bioengineering, Chemical and Biomolecular Engineering, \\ University of California, Berkeley, California 94270, United States
}

\begin{abstract}
The risks of maintaining current $\mathrm{CO}_{2}$ emission trends have led to interest in producing biofuels using engineered microbes. Microbial biofuels reduce emissions because $\mathrm{CO}_{2}$ produced by fuel combustion is offset by $\mathrm{CO}_{2}$ captured by growing biomass, which is later used as feedstock for biofuel fermentation. Hydrocarbons found in petroleum fuels share striking similarity with biological lipids. Here we review synthetic metabolic pathways based on fatty acid and isoprenoid metabolism to produce alkanes and other molecules suitable as biofuels. We further discuss engineering strategies to optimize engineered biosynthetic routes, as well as the potential of synthetic biology for sustainable manufacturing.
\end{abstract}

\section{Introduction}

Over the last century, human use of fossil fuels has raised atmospheric $\mathrm{CO}_{2}$ to levels $40 \%$ higher than at any other time in the 800,000-year record[1,2]. The rising $\mathrm{CO}_{2}$ can be linked to global climate change, including more frequent and intense extreme weather events, andrising mean global temperatures. The already-observedtemperature increase of $0.7^{\circ} \mathrm{C}$ is projected to reach $2-8$ ${ }^{\circ} \mathrm{C}$ by the end of the century, with potentially catastrophic consequences for our biosphere $[1,3]$. 
Of all anthropogenic $\mathrm{CO}_{2}$ emissions, one quarter originate from the combustion of liquid transportation fuels[4]. Curbing these emissions will require a multi-faceted approach, including improved standards for vehicle fuel economy and emissions, alternative-powered vehicles, and biofuels. Biofuels reduce emissions because $\mathrm{CO}_{2}$ produced by fuel combustion is offset by $\mathrm{CO}_{2}$ captured by growing biomass, which is in turn used to produce more fuel(Figure 1). "Drop-in" biofuels that can be used with existing vehicles - especially trucks and planes that are impractical to power using current fuel cell technology—are especially desirable[5]. Stemming from these concerns, severalgovernments including those of the United States, China, and the European Union have instituted mandates for biofuels to constitute an increasing percentage of total transportation fuel usage in the coming years [6].

\section{Liquid transportation fuels}

Today, only $2 \%$ of all transportation fuel is bio-based. By far the most prevalent biofuel is ethanol produced by microbial fermentation of sugars blended into gasoline as a volume booster and oxygenate [7]. However, ethanol can only be used as $10 \%$ of the blend due to its low energy density (and other factors). In the United States, most gasoline is already blended at this $10 \%$ ethanol limit.

Besides ethanol, the other predominant biofuel today is fatty acid alkyl ester (FAAE, marketed as biodiesel). FAAE is produced by thermochemical esterification of plant oils with alcoholtypically methanol or ethanol — and used as a diesel substitute. FAAE is chemically different from petroleum diesel, and from gasoline. Gasoline is primarily composed of linear and ringed C4-C9 hydrocarbons, diesel and jet fuel C8-21. FAAE, on the other hand, is composed of methyl- or ethyl-esters of linear C16-C22 alkyl chains (Figure 2). The increased oxygen content of FAAE leads to more complete fuel combustion, decreasing particulate and $\mathrm{CO}$ emissions [8]. However, oil crops used as feedstocks for FAAE production have low yields and divert agricultural resources from food crops.

The limitations of first-generation biofuels have generated interest in genetically engineering microorganisms to perform the bioconversion of an abundant and inexpensive feedstock into a biofuel. Here we discuss how various enzymes can be combined to biologically produce molecules suitable as transportation fuels, focusingon lipid-based replacements for diesel and jet fuel produced in the two most well-known microbial hosts, Escherichia coli and Saccharomyces 
cerevisiae. We also provide an overview of the tools and methodologies of synthetic biology for creating and optimizing biological designs, and outlooks on its potential for future biomanufacturing.

Figure 1. (high-def color image in separate file)

Carbon cycle for a microbial biofuel. Biofuels reduce emissions because $\mathrm{CO}_{2}$ produced by fuel combustion is offset by $\mathrm{CO}_{2}$ captured by growing biomass, which is in turn used to produce more fuel. With synthetic biology, it may be possible to produce fuel from various sources of carbon and energy. It may also be possible to produce fuels, or other molecules, with improved properties using the diverse bioconversions observed in living organisms.

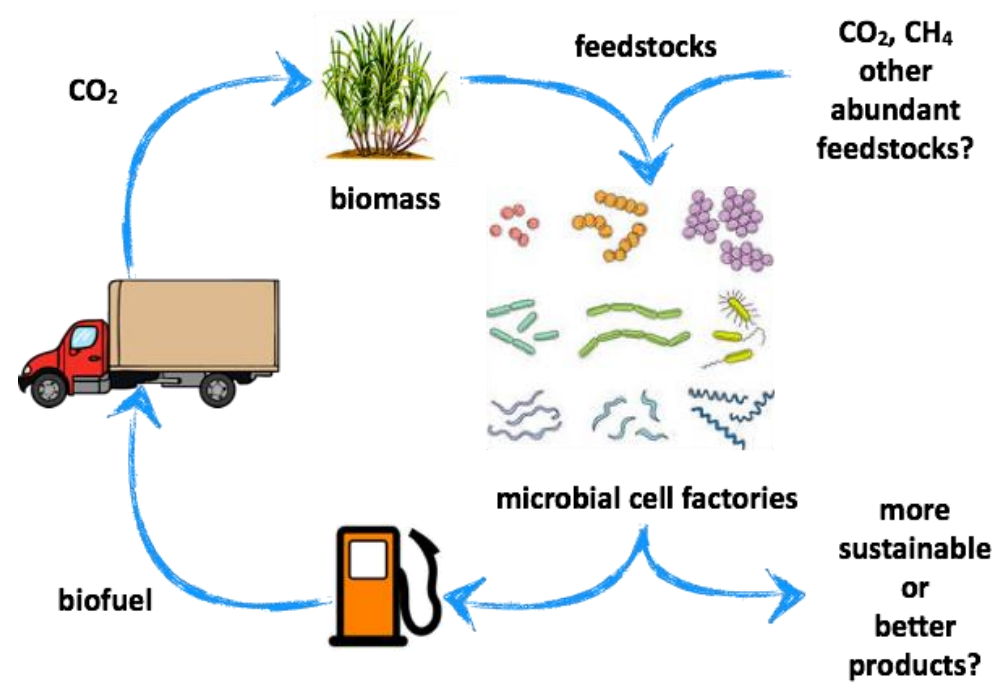

\section{Hydrocarbons and lipids}

The hydrocarbons we use as fuels today sharestriking similarity withsome of the lipids most organisms use to store energy (Figure 2). Lipids are naturally energy-dense, and many exhibit other properties desirable in a biofuel. In fact, early demonstrations of the internal combustion (Diesel) engine used peanut oil as fuel [9]. The triacylglycerides (TAGs) predominant in oils, and other molecules structurally similar to fuels, are produced through the fatty acid biosynthetic pathway. This nearly universally conserved pathway produces some of the major cellular components - e.g., phospholipids and TAGs - and also a great variety of other molecules. 

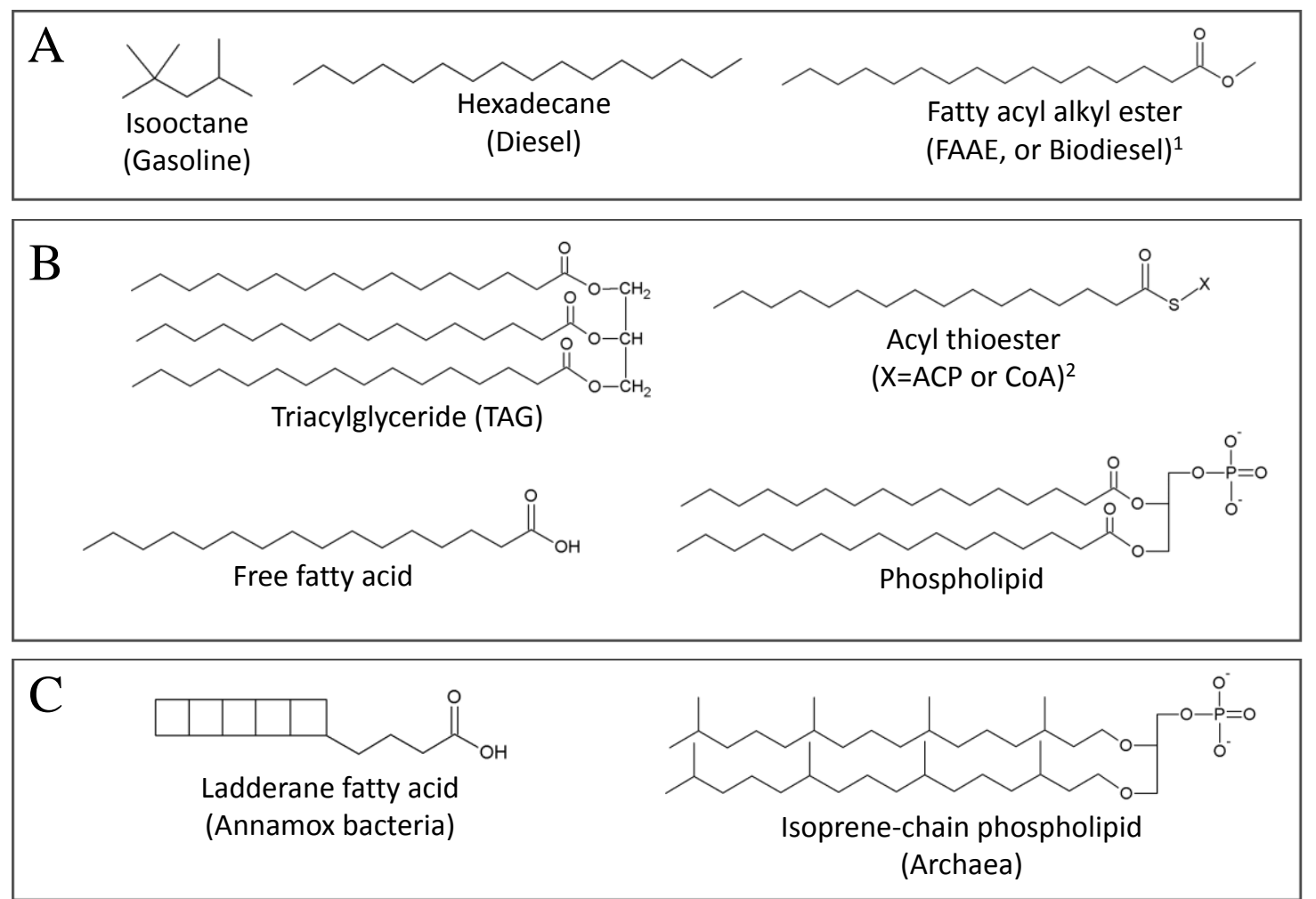

Figure 2 (high-def image in separate file)

Hydrocarbons and lipids. Compounds present in liquid transportation fuels arechemically similartocompounds produced through fatty acid biosynthesis. (A) Iso-octane is a major component of gasoline, hexadecane of diesel fuel, and FAAE of biodiesel. ${ }^{1}$ FAAE is typically produced using methanol and producing fatty acid methyl ester (FAME). (B) TAGs are produced in many organisms as energy storage molecules, and phospholipids as the main structural components of cellular membranes. Fatty acid biosynthesis produces acyl thioester intermediates that give rise to phospholipids, TAGs, and other molecules. ${ }^{2}$ The acyl chains in these thioesters can be bound to acyl carrier protein (ACP) or CoA, depending on the organism. Generally bacteria employ acyl-ACPs and eukaryotes acylCoAs. (C) Lesser-known microorganisms contain intriguing lipids. Annamox bacteria produce fatty acids containing linearly concatenated cyclobutane rings termed "ladderanes". Archaeal membranes are composed of phospholipids containing isoprenechains linked through ether (rather than ester) linkages.

Fatty acid metabolism 
Fatty acid metabolism begins with the carboxylation of acetyl-CoA to malonyl-CoA by acetylCoA carboxylase (ACC). Fatty acid synthase (FAS) then condenses one acetyl-CoA starter unit and several malonyl-CoA extender units iteratively to produce a linear acyl chain typically 12-22 carbons long, depending on the organism. Fatty acids are released as acyl thioesters, bound to either coenzyme A (CoA, in type I FAS) or to acyl carrier protein (ACP, in type II FAS). Most fungi and mammals employ type I FAS, most bacteria type II. Type II FAS is organized as discrete multifunctional polypeptides. By contrast type I FAS is organized as multimeric complexes of one or more polypeptides, each containing multiple enzyme activities.

After synthesis, acyl thioesters are mainly routed biologically toward membrane phospholipids (containing two acyl chains bound to a glycerol backbone) or energy storage TAGs (containing three). Most organisms can degrade TAGs or other fatty acids through $\beta$-oxidation. Some organisms perform additional bioconversions, such asconsuming alkanes [10], or producing wax esters, polyhydroxyalkanoates, fatty alcohols, orother compounds through variations of this versatile pathway.

\section{Engineered microbial production of fatty-acid derived biofuels}

Genes encoding enzymes that perform desired chemical conversions can be introduced into an easy-to-culture and genetically tractable microbial host, allowing the engineered strain to convert a simple feedstock - e.g., glucose — into a target molecule. A number of enzymes have been identified that catalyze the conversion of fatty acids or their intermediates into different products with good fuel properties.

FAAE — molecularly identical to oil-crop biodiesel — has been produced by heterologously expressing a wax ester synthase (WS) catalyzing the esterification of an acyl thioester with ethanol $[11,12]$. Several WS enzymes have been shown to catalyze this reaction [13].

Alkanes and alkenes - the major constituents of petroleum diesel-have been produced through various bioengineered routes, such as the reduction of acyl-thioesters (or free fatty acids) into fatty aldehydes followed by decarbonylation [14-16]. Other routes include the decarboxylation of free fatty acids directly into $\alpha$-alkenes by a bacterial cytochrome P450 [16], or polyketide synthase(PKS)-mediated extension-decarboxylation[17]. 
Similarly, different pathways can be assembled to produce molecules not currently used as fuels, but with likely suitable properties, including fatty alcohols $[12,18]$, methyl ketones $[19,20], \omega-$ hydroxy and dicarboxylic acids [21], and other fatty acid-derived products (Figure 3). It should be noted that different tailoring enzymes have different preferences for substrate chain length and terminal moiety, e.g., acyl-ACP, acyl-CoA, or free fatty acids. These can mirror the nature of their host's central FAS pathway - type I produces acyl-CoA, type II acyl-ACP. However, it is possible to introduce a type I FAS pathway into a host that natively employs type II FAS [22], or vice-versa [23]. Additionally, the FAS pathway can be modified to incorporate branched amino acids and produce branched-chain fatty acids[24]. Chain branching lowers freezing point, which is important for fuel performance in high altitudes or cold weather.

\section{Isoprenoid metabolism}

Branching is a defining feature of isoprenoids, another main class of lipids that produces molecules similar to those found in fuels. Also called terpenoids, these molecules are defined by being formed from 5-carbon isoprene building blocks into thousands of molecules, encompassing60\% of known natural products[25]. Isoprenoids are better known as plant secondary metabolites. However they perform diverse functions in all kingdoms of life. In archaea, for example, isoprenoids are part of primary metabolism and comprise the hydrophobic chains of cell membranes (Figure 2).

Isoprenoidsare synthesized through one of two pathways: the 1-deoxy-D-xylulose 5-phosphate (DXP) pathway (native to most bacteria) or the mevalonate (MVA) pathway (native to most eukaryotes and archaea). The MVA pathway begins with three acetyl-CoA molecules, which combine to form mevalonate through six enzyme-catalyzed steps. The DXP pathway begins with pyruvate and glyceraldehyde-3-phosphate, which formDXP through seven steps. Both pathways proceed further to form the five-carbon building blocks isopentenyl pyrophosphate (IPP) and dimethylallyl pyrophosphate (DMAPP). IPP and DMAPPcan be condensed and modified in various ways by various kinds of terpene synthases (TPSs) to form thousands of products. C10 and C15 isoprenoids, called respectively monoterpenes and sesquiterpenes, have appropriate carbon numbers for a liquid biofuel.

\section{Engineered microbial production of isoprenoid derived biofuels}

Monoterpenes (C10) are produced by the condensation of IPP and DMAPP into geranyl pyrophosphate (GPP) catalyzed by GPP synthase, and further modified by any number of 
monoterpene synthases. Synthetic pathways to monoterpenes such as $\alpha$-pinene [26],sabinene [27], limonene [28], and geraniol [29], have been successfully constructed in microbial hosts.

Sesquiterpenes (C15) are produced by the condensation of two IPP molecules and one DMAPP into farnesyl pyrophosphate (FPP) by FPP synthase, and subsequent modification by sesquiterpene synthases. Combining pathways to FPP with various sesquiterpene synthasesin microbial hosts has produced bisabolene [30] and $\alpha$-farnesene [31].

Figure 3(high-def color image in separate file)

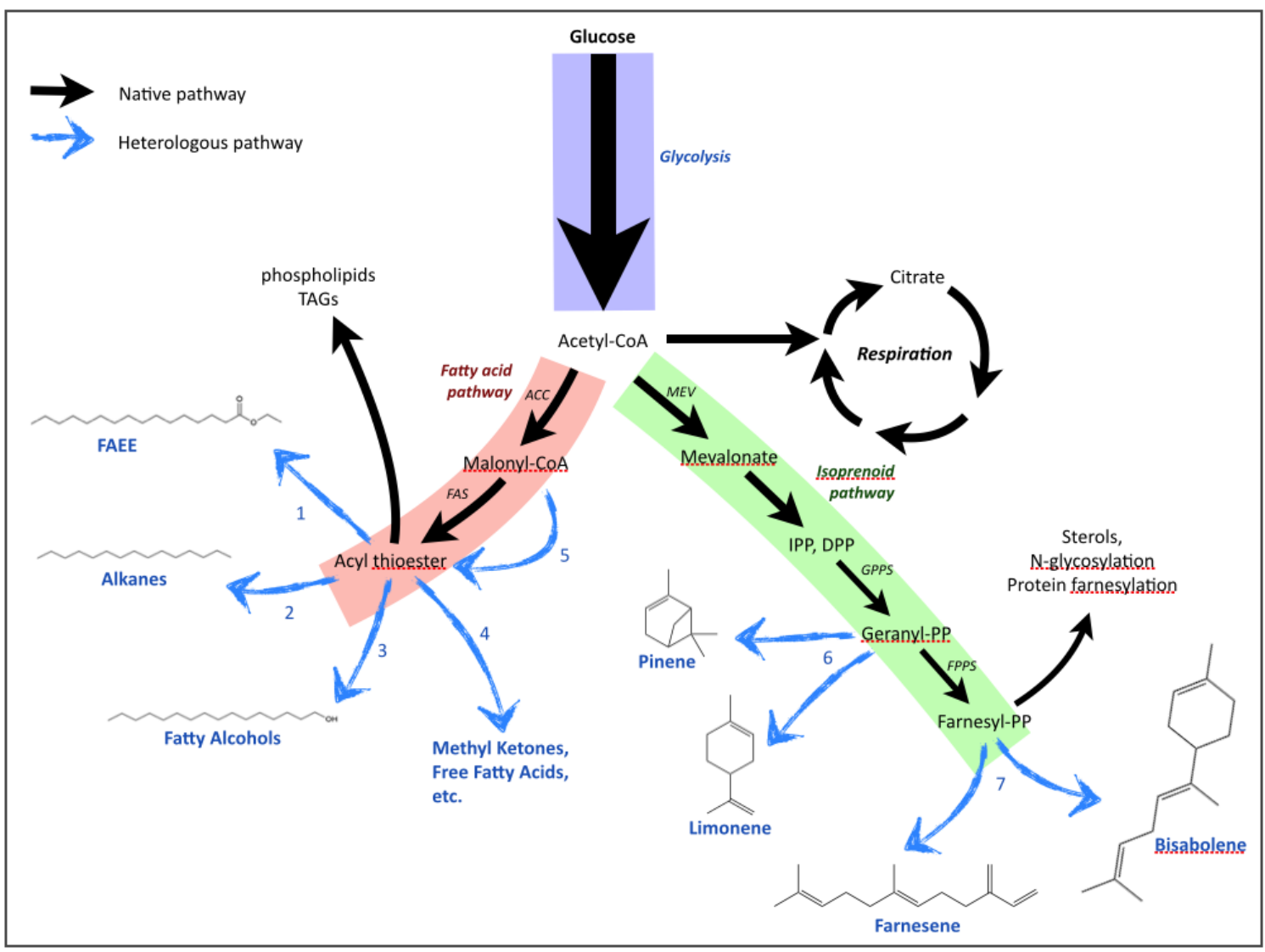

Biosynthetic routes for the production of natural and synthetic fuels from glucose. Fatty acid biosynthesis (pink)naturally produces phospholipids for membrane composition, and TAGs for energy storage. Isoprenoid biosynthesis (green) naturally produces sterols and other compounds. These pathways can be coopted using heterologous genes to produce a number of biofuel molecules. From acyl thioesters: 1, Esterification with ethanol by wax synthase [11] to produce FAEE; 2, Reduction followed by decarbonylation [14-16], or PKS- 
mediatedextension-decarboxylation [32] to produce alkanes/enes; 3, Reduction either directly [22] or through fatty aldehydes intermediates[18] to produce fatty alcohols; 4, Other routes to other products [12,19]; 5, Heterologous FAS pathways [22,23];

6,Monoterpene synthases can modify $\mathrm{C} 10$ geranyl-PP to produce pinene, limonene, or other monoterpenes [28,33]; 7,Sesquiterpene synthases can modify C15 Farnesyl-PP to form farnesene, bisabolene, or other sesquiterpenes[30,31]. Unsaturated lipids can be chemically hydrogenated for biofuel production (e.g., farnesene to farnesane). ACC, acetyl-CoA carboxylase; FAS, fatty acid synthase. The isoprenoid pathway shown is the mevalonate (MEV) pathway. Bacteria employ an alternative route, the DXP pathway, not shown for simplicity.

\section{Metabolic engineering strategies for lipid-based biofuels}

Having chosen a set of enzyme activities as a biosynthetic route to a biofuel, achieving good production levels is often challenging and time-consuming. Traditional metabolic engineering often employs a"pull-push-block" approach. "Pulling" on a pathway by overexpressing terminal enzymes or providing an irreversible sink — such as partitioning into a separate phase [12] — can create a thermodynamic driving force for product formation. "Blocking" consumption of products or intermediates can be achieved by deleting genes catalyzing undesirable reactions $[12,34,35]$. "Pushing" flux involves overcoming bottlenecks that mayform along the pathway. The problems, and solutions, are oftenspecific to the pathway and host organism.

In fatty acid biosynthesis, for example, a common bottleneck is the carboxylation of acetyl-CoA into malonyl-CoA by ACC [36].In E. coli, ACC activity is inhibited by the product acyl-ACP. This inhibition can be minimized by converting acyl-ACP to other products that do not inhibit ACC - e.g., by expressing a thioesterase [12]. In S. cerevisiae, ACC activity is inhibited posttranslationally byphosphorylation in response to signals — such as glucose depletion. Mutating phosphorylation sites in ACC has resulted in increased titers of fatty acid products [37]. Another layer of regulation in yeast is transcriptional inhibition of ACC in response to elevated fatty acid levels. Replacing the native ACC promoter with one that is constitutivelyactive has led to improved fatty product titers [34].

The availability of the central metabolite acetyl-CoA is important not only for fatty acid-derived products, but also isoprenoids produced through the mevalonate pathway, and many other targets. In S. cerevisiae, acetyl-CoA is provided to different subcellular pools through various 
biosynthetic routes [38]. The route to cytoplasmic acetyl-CoA is energetically draining and suppressed in the high-glucose conditions typical of laboratory and industrial cultivation(for reasons that arestill debated[39,40]). Strategies to overcome this bottleneck have included expressing heterologous pathways for the provision of this central building block[41-44].

A number of other strategies (reviewedelsewhere [45-48])have been used to improve production levels of many biofuel molecules (Table 1). While many improvements in production levels have been realized, there is much room for further optimization to approach maximum theoretical yields.

TABLE 1. Yields of lipid fuels produced in engineered $E$. coli and $S$. cerevisiae

\begin{tabular}{|c|c|c|c|c|c|c|}
\hline Biofuel & $\begin{array}{c}\text { Max } \\
\text { Theoretical }^{\text {Yield }}{ }^{A} \\
\text { (g/g } \text { glucose })^{-}\end{array}$ & Host & $\begin{array}{l}\text { Titer } \\
(g / L)\end{array}$ & $\begin{array}{c}\text { Yield } \\
(\text { g/g glucose })\end{array}$ & $\begin{array}{l}\text { Percent of } \\
\text { Max } \\
\text { Theoretical }^{\text {Mield }}\end{array}$ & Reference \\
\hline \multirow{2}{*}{$\begin{array}{r}F F A \\
(C 16)\end{array}$} & \multirow[t]{2}{*}{0.37} & E. coli & 7.0 & 0.28 & $76 \%$ & [49] \\
\hline & & S. cerevisiae & 2.2 & 0.11 & $30 \%$ & [35] \\
\hline \multirow{2}{*}{$\begin{array}{r}\text { FAEE } \\
(C 18)\end{array}$} & \multirow[t]{2}{*}{0.36} & E. coli & 1.5 & 0.075 & $21 \%$ & [50] \\
\hline & & S. cerevisiae & 0.034 & 0.0017 & $<1 \%$ & [13] \\
\hline \multirow{2}{*}{$\begin{array}{r}\text { Fatty alcohol } \\
\text { (C16) }\end{array}$} & \multirow[t]{2}{*}{0.34} & E. coli & $3.8^{\mathrm{B}}$ & 0.13 & $38 \%$ & [22] \\
\hline & & S. cerevisiae & 1.1 & 0.055 & $16 \%$ & [18] \\
\hline \multirow{2}{*}{$\begin{array}{r}\text { Alkanes } \\
(\text { C15) }\end{array}$} & \multirow[t]{2}{*}{0.30} & E. coli & 0.58 & 0.029 & $8 \%^{C}$ & [15] \\
\hline & & S. cerevisiae & 0.0037 & 0.00019 & $<1 \%$ & [51] \\
\hline \multirow{2}{*}{$\begin{array}{r}\text { Bisabolene } \\
\text { (C15) }\end{array}$} & \multirow[t]{2}{*}{0.27} & E. coli & 1.1 & 0.055 & $20 \%$ & [52] \\
\hline & & S. cerevisiae & 1.0 & 0.050 & $19 \%$ & {$[30]$} \\
\hline
\end{tabular}

Titers and yields of current laboratory-scale demonstrations of selected microbial biofuels produced in $E$. coli and $S$. cerevisiae. In general, experiments were performed using $2 \%$ glucose in shake flask fermentations.

${ }^{\text {A }}$ Maximum theoretical yields are calculated using an in silico optimization algorithm employing a whole genome-scale reconstruction [53,54].

${ }^{B}$ This example used $3 \%$ glucose rather than $2 \%$.

${ }^{\mathrm{C}}$ This example produced $\mathrm{C} 8$ alkanes, with a different maximum theoretical yield, which is nevertheless accounted for in the percent yield calculation.

Synthetic biology tools and methodologies 
Synthetic biology today encompasses an increasing number of tools and methodologies to facilitate strain construction and optimization. Synthesizing, sequencing, and introducing DNA sequences into living cells [55] is cheaper and easier than ever. Codon-optimization, directed evolution [56], screening enzyme libraries, and incorporating non-natural amino acids[57] all provide ways of improving or generating novel enzymatic activities.

Moving beyond which genes to express (or delete), how to express them-when, where, and at what level — can have significant effects on the growth rate and product titer of engineered strains. It is a defining feature of biological systems that their constituent parts are interconnected - as compared to electrical circuits or chemical engineering unit operations. More fully characterizing and modeling biological systems will reveal principles and design rules for synthetic biology [52,58]. These can be implemented using an increasing number of tools to programgene expression: ribosome binding sites (RBSs)[59], promoters[60], trans-acting activators[61], sensors and switches[50,62], enzyme fusions [63], scaffolds [64], localization tags [65], and other genetic "parts". Employing these in ways approaching the complex natural orchestration of metabolism [66] will be necessary for more sophisticated and better performing biological designs.

While we have constrained our discussion to S. cerevisiae and E. coli, several other microorganisms are already used as hosts for engineered bioproduction [67]. A different host organism may have a significantly different base metabolism, availability of substrates and cofactors, or compatibility with heterologous genes, which can lead to better pathways. Exploring and developing genetic tools for non-traditional hosts will open possibilities for novel metabolic pathways.

\section{Conclusions}

With more powerful synthetic biology tools, the concept of "host" gives way to a fundamentally different synthetic organism. It's worth considering how thedesign objectives differ between a natural organism that evolved to maximize fitness in a given ecological niche, and one synthetically constructed to convert a feedstock into a product. How to realize these radically different objectives is a current aim in synthetic biology. The propensity of organisms to growrather than to necessarily produce a target molecule — can lead to lower product yields. The propensity to mutate - perhaps necessary to adapt to changing environmental conditions - may 
not be desirable in constant fermentation conditions, and in fact yield to strain instability. Many of these concerns have significant impacts on the viability of microbial bioproduction.

For biofuels, strain performance isparamount. A gallon of petroleum gasoline sells for less than a gallon of water [68]. Techno-economic analysisshows that microbial biofuels provide for significant reductions in $\mathrm{CO}_{2}$ emissions over using petroleum fuels [69]. However, these savings, and the economic viability of such bioprocesses, depend largely on biochemical pathway yields and feedstock costs. Bioprocesses that utilize as feedstock cellulosic biomass - agricultural or wood industry by-products, grasses growing on marginal land, etc. - offer maximal $\mathrm{CO}_{2}$ offsets, and don't compete with food production [70]. In the future it may be possible to engineer strains that grow directly on cellulosic biomass, or other abundant and inexpensive substrates, such as methane or $\mathrm{CO}_{2}$. Or it may be possible to produce molecules with better performance, or as yet unimagined uses.As synthetic biology matures, this young technology holds vast potential tosupplant the fossil economy with a sustainable and versatile biomanufacturing platform.

\section{Acknowledgements}

We thank Nicholas Clements, Victor Chubukov, and Maren Wehrs for suggestions while preparing this manuscript. This work was funded by the Joint BioEnergy Institute (JBEI), which is funded by the U.S. Department of Energy, Office of Science, Office of Biological and Environmental Research, under Contract DE-AC02-05CH11231. 


\section{References}

(Literature highlights are included in the separate "highlights" file)

1. Pachauri RK, Meyer L, Van Ypersele J-P, Brinkman S, Van Kesteren L, Leprince-Ringuet N, Van Boxmeer F: IPCC Climate Change 2014 Synthesis Report [Internet]. 2014.

2. Dlugokencky E, Tans P: Trends in Atmospheric Carbon Dioxide [Internet]. 2015.

3. Wood RA, Vellinga M, Thorpe R: Global warming and thermohaline circulation stability. [Internet]. Philos. Trans. A. Math. Phys. Eng. Sci. 2003, 361:1961-74; discussion 1974-5.

4. CO2 Emissions From Fuel Combustion: Highlights (2014 Edition). 2014.

5. Sousanis J: World Vehicle Population Tops 1 Billion Units [Internet]. WardsAuto 2011, [no volume].

6. Lane J: Biofuels Mandates Around the World 2015 [Internet]. Biofuels Dig. 2015, [no volume].

7. Gomez J, Brasil T, Chan N: An Overview of the Use of Oxygenates in Gasoline. 1998.

8. Liu H, Bi X, Huo M, Lee CFF, Yao M: Soot Emissions of Various Oxygenated Biofuels in Conventional Diesel Combustion and Low-Temperature Combustion Conditions. Energy and Fuels 2012, 26:1900-1911.

9. Diesel R: The Diesel oil-engine. Engineering 1912, 93:395-406.

10. Zengler K, Richnow HH, Rosselló-Mora R, Michaelis W, Widdel F: Methane formation from long-chain alkanes by anaerobic microorganisms. [Internet]. Nature 1999, 401:266-9.

11. Kalscheuer R, Stölting T, Steinbüchel A: Microdiesel: Escherichia coli engineered for fuel production. Microbiology 2006, 152:2529-2536. 
12. Steen EJ, Kang Y, Bokinsky G, Hu Z, Schirmer A, McClure A, Del Cardayre SB, Keasling JD: Microbial production of fatty-acid-derived fuels and chemicals from plant biomass. [Internet]. Nature 2010, 463:559-62.

13. Shi S, Valle-Rodríguez JO, Khoomrung S, Siewers V, Nielsen J: Functional expression and characterization of five wax ester synthases in Saccharomyces cerevisiae and their utility for biodiesel production. [Internet]. Biotechnol. Biofuels 2012, 5:7.

14. Schirmer A, Rude M a, Li X, Popova E, del Cardayre SB: Microbial biosynthesis of alkanes. [Internet]. Science 2010, 329:559-62.

15. Choi YJ, Lee SY: Microbial production of short-chain alkanes [Internet]. Nature 2013, 502:571-4.

16. Liu Y, Wang C, Yan J, Zhang W, Guan W, Lu X, Li S: Hydrogen peroxide-independent production of $\alpha$-alkenes by OleTJE P450 fatty acid decarboxylase.Biotechnol. Biofuels 2014, 7:28.

17. Liu Q, Wu K, Cheng Y, Lu L, Xiao E, Zhang Y, Deng Z, Liu T: Engineering an iterative polyketide pathway in Escherichia coli results in single-form alkene and alkane overproduction. Metab. Eng. 2015, 28:82-90.

18. Feng X, Lian J, Zhao H: Metabolic engineering of Saccharomyces cerevisiae to improve 1-hexadecanol production [Internet]. Metab. Eng. 2014, 27:10-19.

19. Goh E-B, Baidoo EEK, Burd H, Lee TS, Keasling JD, Beller HR: Substantial improvements in methyl ketone production in E. coli and insights on the pathway from in vitro studies [Internet]. Metab. Eng. 2014, 26:67-76.

20. Goh E-B, Baidoo EEK, Keasling JD, Beller HR: Engineering of bacterial methyl ketone synthesis for biofuels. [Internet]. Appl. Environ. Microbiol. 2012, 78:70-80.

21. Clomburg JM, Blankschien MD, Vick JE, Chou A, Kim S, Gonzalez R: Integrated engineering of $\beta$-oxidation reversal and $\omega$-oxidation pathways for the synthesis of medium chain $\omega$-functionalized carboxylic acids [Internet]. Metab. Eng. 2015, 28:202-212. 
22. Haushalter RW, Groff D, Deutsch S, The L, Chavkin T a., Brunner SF, Katz L, Keasling JD: Development of an orthogonal fatty acid biosynthesis system in E. coli for oleochemical production [Internet]. Metab. Eng. 2015, 30:1-6.

23. Fernandez-Moya R, Leber C, Cardenas J, Da Silva NA: Functional replacement of the Saccharomyces cerevisiae fatty acid synthase with a bacterial type II system allows flexible product profiles. [Internet]. Biotechnol. Bioeng. 2015, doi:10.1002/bit.25679.

24. Haushalter RW, Kim W, Chavkin TA, The L, Garber ME, Nhan M, Adams PD, Petzold CJ, Katz L, Keasling JD: Production of anteiso-branched fatty acids in Escherichia coli; next generation biofuels with improved cold-flow properties. [Internet]. Metab. Eng. 2014, 26C:111-118.

25. Firn R: Nature's Chemicals: The Natural Products that Shaped Our World. Oxford University Press; 2010.

26. Yang J, Nie Q, Ren M, Feng H, Jiang X, Zheng Y, Liu M, Zhang H, Xian M: Metabolic engineering of Escherichia coli for the biosynthesis of alpha-pinene. [Internet]. Biotechnol. Biofuels 2013, 6:60.

27. Zhang H, Liu Q, Cao Y, Feng X, Zheng Y, Zou H, Liu H, Yang J, Xian M: Microbial production of sabinene--a new terpene-based precursor of advanced biofuel. [Internet]. Microb. Cell Fact. 2014, 13:20.

28. Alonso-Gutierrez J, Chan R, Batth TS, Adams PD, Keasling JD, Petzold CJ, Lee TS: Metabolic engineering of Escherichia coli for limonene and perillyl alcohol production. [Internet]. Metab. Eng. 2013, 19:33-41.

29. Zhou J, Wang C, Yoon S-H, Jang H-J, Choi E-S, Kim S-W: Engineering Escherichia coli for selective geraniol production with minimized endogenous dehydrogenation. [Internet]. J. Biotechnol. 2014, 169:42-50.

30. Peralta-Yahya PP, Ouellet M, Chan R, Mukhopadhyay A, Keasling JD, Lee TS: Identification and microbial production of a terpene-based advanced biofuel. [Internet]. Nat. Commun. 2011, 2:483. 
31. Wang C, Yoon S-H, Jang H-J, Chung Y-R, Kim J-Y, Choi E-S, Kim S-W: Metabolic engineering of Escherichia coli for $\boldsymbol{\alpha}$-farnesene production. [Internet]. Metab. Eng. 2011, 13:648-55.

32. Mendez-Perez D, Begemann MB, Pfleger BF: Modular synthase-encoding gene involved in alpha-olefin biosynthesis in Synechococcus sp. strain pcC 7002. Appl. Environ. Microbiol. 2011, 77:4264-4267.

33. Sarria S, Wong B, García Martín H, Keasling JD, Peralta-Yahya P, Martín HG, Keasling JD, Peralta-Yahya P: Microbial synthesis of pinene. [Internet]. ACS Synth. Biol. 2014, 3:466-75.

34. Runguphan W, Keasling JD: Metabolic Engineering of Saccharomyces cerevisiae for Production of Fatty Acid-Derived Biofuels and Chemicals. [Internet]. Metab. Eng. 2013, doi:10.1016/j.ymben.2013.07.003.

35. Leber C, Polson B, Fernandez-Moya R, Da Silva N a: Overproduction and secretion of free fatty acids through disrupted neutral lipid recycle in Saccharomyces cerevisiae. [Internet]. Metab. Eng. 2014, 28:54-62.

36. Trotter P: The genetics of fatty acid metabolism in Saccharomyces cerevisiae [Internet]. Annu. Rev. Nutr. 2001, [no volume].

37. Shi S, Chen Y, Siewers V: Improving Production of Malonyl Coenzyme A-Derived Metabolites. MBio 2014, doi:10.1128/mBio.01130-14.Editor.

38. Chen Y, Siewers V, Nielsen J: Profiling of cytosolic and peroxisomal acetyl-CoA metabolism in Saccharomyces cerevisiae. [Internet]. PLoS One 2012, 7:e42475.

39. Pfeiffer T, Morley A: An evolutionary perspective on the Crabtree effect. [Internet]. Front. Mol. Biosci. 2014, 1:17.

40. Hagman A, Säll T, Compagno C, Piskur J: Yeast “make-accumulate-consume” life strategy evolved as a multi-step process that predates the whole genome duplication. [Internet]. PLoS One 2013, 8:e68734. 
41. Shiba Y, Paradise EM, Kirby J, Ro D-K, Keasling JD: Engineering of the pyruvate dehydrogenase bypass in Saccharomyces cerevisiae for high-level production of isoprenoids. [Internet]. Metab. Eng. 2007, 9:160-8.

42. Tang X, Feng H, Chen WN: Metabolic engineering for enhanced fatty acids synthesis in Saccharomyces cerevisiae. [Internet]. Metab. Eng. 2013, 16:95-102.

43. Kozak BUB, van Rossum HM, Luttik MMAH, Akeroyd M, Benjamin KR, Wu L, de Vries S, Daran J-M, Pronk JT, van Maris AJA, et al.: Engineering Acetyl Coenzyme A Supply: Functional Expression of a Bacterial Pyruvate Dehydrogenase Complex in the Cytosol of Saccharomyces cerevisiae [Internet]. MBio 2014, 5:e01696-14.

44. Sonderegger M, Schümperli M, Sauer U: Metabolic engineering of a phosphoketolase pathway for pentose catabolism in Saccharomyces cerevisiae. [Internet]. Appl. Environ. Microbiol. 2004, 70:2892-7.

45. Janßen HJ, Steinbüchel A: Fatty acid synthesis in Escherichia coli and its applications towards the production of fatty acid based biofuels. [Internet]. Biotechnol. Biofuels 2014, 7:7.

46. Lennen RM, Pfleger BF: Microbial production of fatty acid-derived fuels and chemicals. [Internet]. Curr. Opin. Biotechnol. 2013, 24:1044-1053.

47. Krivoruchko A, Zhang Y, Siewers V, Chen Y, Nielsen J: Microbial acetyl-CoA metabolism and metabolic engineering [Internet]. Metab. Eng. 2014, 28:1-15.

48. Zhou YJ, Buijs N a., Siewers V, Nielsen J: Fatty Acid-Derived Biofuels and Chemicals Production in Saccharomyces cerevisiae [Internet]. Front. Bioeng. Biotechnol. 2014, 2:1-6.

49. Dellomonaco C, Clomburg JM, Miller EN, Gonzalez R: Engineered reversal of the $\boldsymbol{\beta}$ oxidation cycle for the synthesis of fuels and chemicals. [Internet]. Nature 2011, 476:355-9. 
50. Zhang F, Carothers JM, Keasling JD: Design of a dynamic sensor-regulator system for production of chemicals and fuels derived from fatty acids. [Internet]. Nat. Biotechnol. 2012, 30:354-9.

51. Binbin C, Lee D-Y, Matthew Wook C: Combinatorial metabolic engineering of Saccharomyces cerevisiae for terminal alkene production. Metab. Eng. 2015, [no volume].

52. Alonso-Gutierrez J, Kim E-M, Batth TS, Cho N, Hu Q, Chan LJG, Petzold CJ, Hillson NJ, Adams PD, Keasling JD, et al.: Principal component analysis of proteomics (PCAP) as a tool to direct metabolic engineering. [Internet]. Metab. Eng. 2015, 28:123-33.

53. Pfleger BF, Gossing M, Nielsen J: Metabolic engineering strategies for microbial synthesis of oleochemicals [Internet]. Metab. Eng. 2015, 29:1-11.

54. Caspeta L, Buijs $\mathrm{N}$ a. a., Nielsen $\mathrm{J}$ : The role of biofuels in the future energy supply [Internet]. Energy Environ. Sci. 2013, 6:1077.

55. DiCarlo JE, Norville JE, Mali P, Rios X, Aach J, Church GM: Genome engineering in Saccharomyces cerevisiae using CRISPR-Cas systems. [Internet]. Nucleic Acids Res. 2013, 41:4336-43.

56. Korman TP, Sahachartsiri B, Charbonneau DM, Huang GL, Beauregard M, Bowie JU: Dieselzymes: development of a stable and methanol tolerant lipase for biodiesel production by directed evolution. [Internet]. Biotechnol. Biofuels 2013, 6:70.

57. Cirino PC, Tang Y, Takahashi K, Tirrell D a., Arnold FH: Global incorporation of norleucine in place of methionine in cytochrome P450 BM-3 heme domain increases peroxygenase activity. Biotechnol. Bioeng. 2003, 83:729-734.

58. Chowdhury A, Zomorrodi AR, Maranas CD: k-OptForce: integrating kinetics with flux balance analysis for strain design. [Internet]. PLoS Comput. Biol. 2014, 10:e1003487.

59. Xu P, Gu Q, Wang W, Wong L, Bower AGW, Collins CH, Koffas MAG: Modular optimization of multi-gene pathways for fatty acids production in E. coli. [Internet]. Nat. Commun. 2013, 4:1409. 
60. Latimer LN, Lee ME, Medina-Cleghorn D, Kohnz RA, Nomura DK, Dueber JE: Employing a combinatorial expression approach to characterize xylose utilization in Saccharomyces cerevisiae. [Internet]. Metab. Eng. 2014, 25C:20-29.

61. Gilbert L a, Larson MH, Morsut L, Liu Z, Brar G a, Torres SE, Stern-Ginossar N, Brandman O, Whitehead EH, Doudna J a, et al.: CRISPR-mediated modular RNAguided regulation of transcription in eukaryotes. [Internet]. Cell 2013, 154:442-51.

62. Li S, Si T, Wang M, Zhao H: Development of a Synthetic Malonyl-CoA Sensor in Saccharomyces cerevisiae for Intracellular Metabolite Monitoring and Genetic Screening. [Internet]. ACS Synth. Biol. 2015, doi:10.1021/acssynbio.5b00069.

63. Albertsen L, Chen Y, Bach LS, Rattleff S, Maury J, Brix S, Nielsen J, Mortensen UH: Diversion of flux toward sesquiterpene production in Saccharomyces cerevisiae by fusion of host and heterologous enzymes. [Internet]. Appl. Environ. Microbiol. 2011, 77:1033-40.

64. Sachdeva G, Garg A, Godding D, Way JC, Silver PA: In vivo co-localization of enzymes on RNA scaffolds increases metabolic production in a geometrically dependent manner. [Internet]. Nucleic Acids Res. 2014, 42:9493-503.

65. Avalos JL, Fink GR, Stephanopoulos G: Compartmentalization of metabolic pathways in yeast mitochondria improves the production of branched-chain alcohols. [Internet]. Nat. Biotechnol. 2013, 31:335-41.

66. Chubukov V, Gerosa L, Kochanowski K, Sauer U: Coordination of microbial metabolism. [Internet]. Nat. Rev. Microbiol. 2014, 12:327-40.

67. Qiao K, Imam Abidi SH, Liu H, Zhang H, Chakraborty S, Watson N, Kumaran Ajikumar P, Stephanopoulos G: Engineering lipid overproduction in the oleaginous yeast Yarrowia lipolytica [Internet]. Metab. Eng. 2015, 29:56-65.

68. Thompson D: Gas Prices Around the World: Cheaper Than Water and \$10 a Gallon The Atlantic [Internet]. Atl. 2011, [no volume]. 
69. Caspeta L, Nielsen J: Economic and environmental impacts of microbial biodiesel. [Internet]. Nat. Biotechnol. 2013, 31:789-93.

70. Perlack RD, Stokes BJ: U.S. Billion-Ton Update: Biomass Dupply for a Bioenergy and Bioproducts Industry. 2011. 


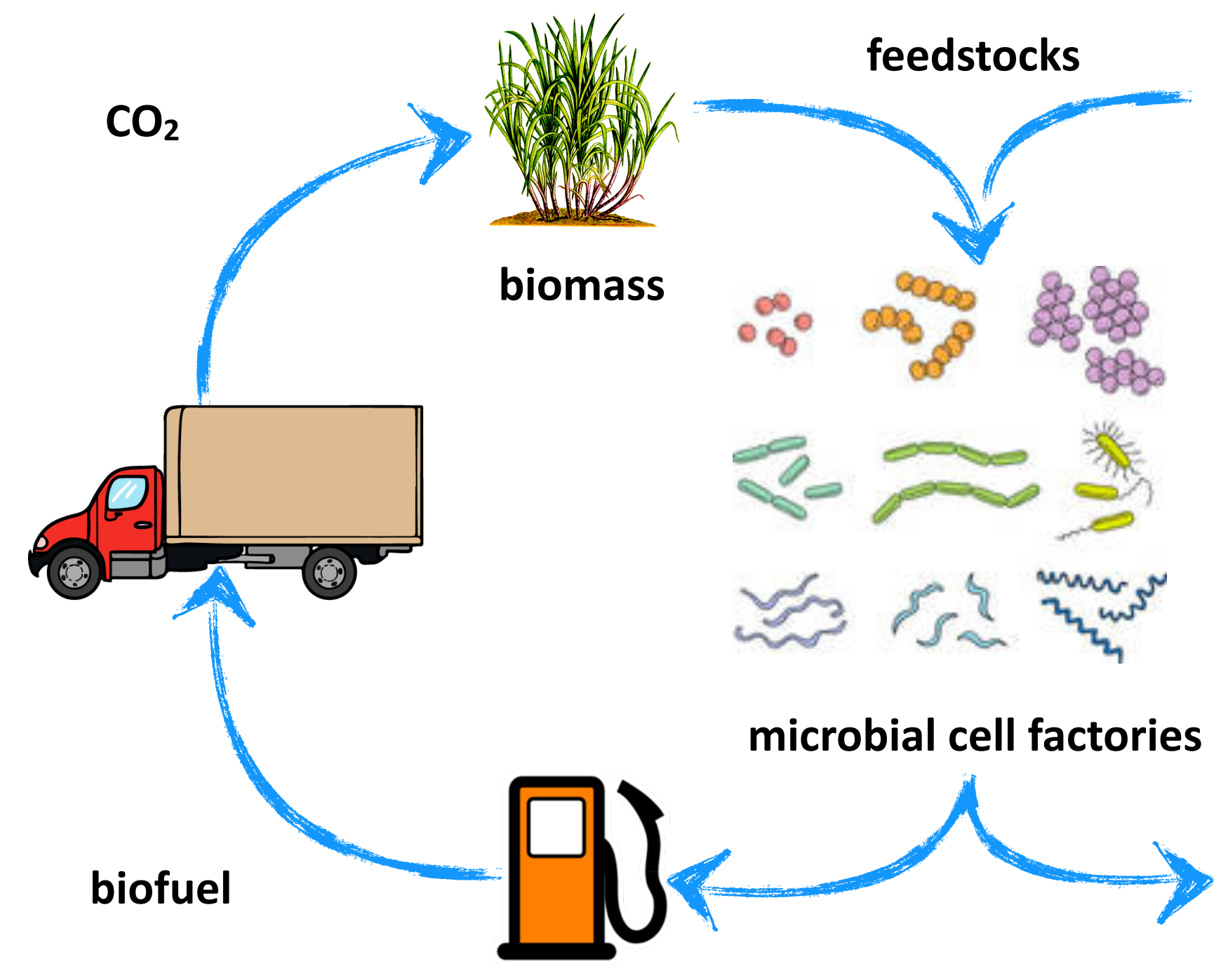

$\mathrm{CO}_{2}, \mathrm{CH}_{4}$ other abundant feedstocks?

more sustainable or better products?

\section{FIGURE 1}



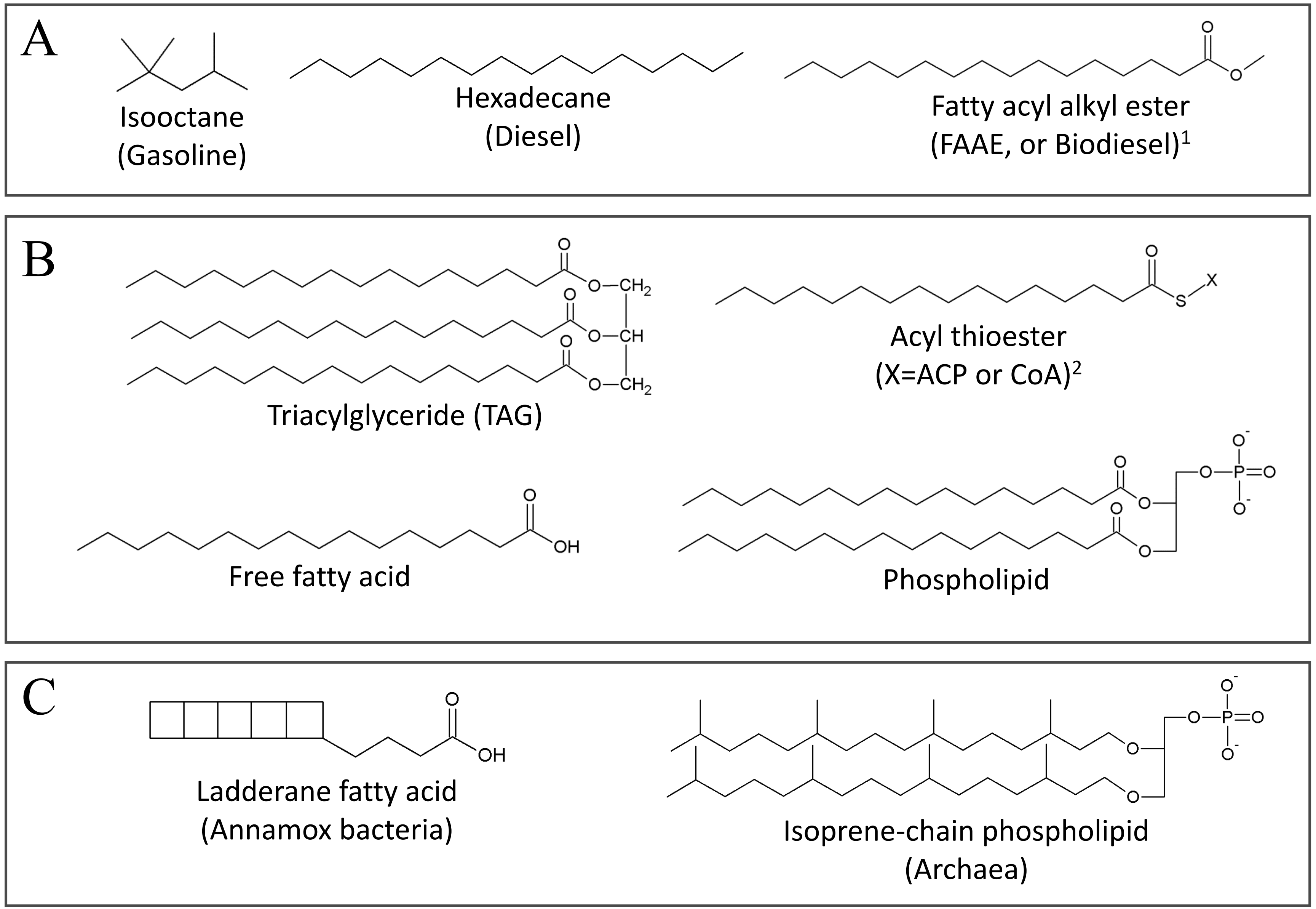

\section{FIGURE 2}




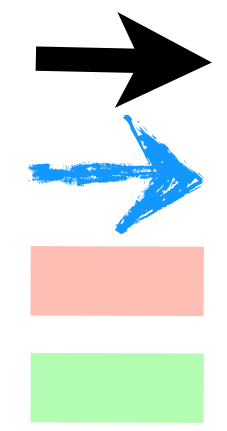

Native pathway

Heterologous pathway

Fatty acid biosynthetic pathway

Isoprenoid biosynthetic pathway

\section{Glucose}

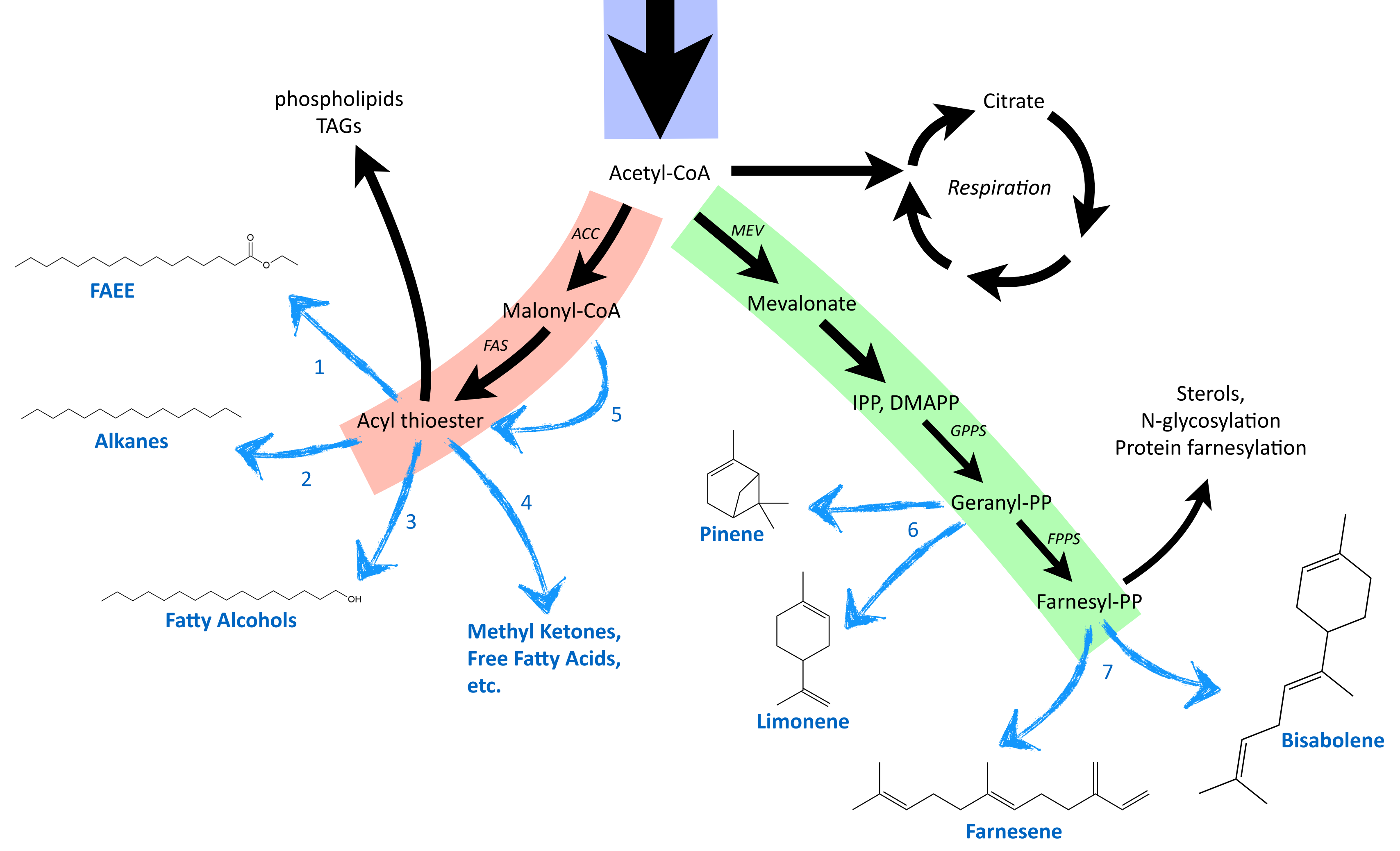


Dear Editor and Reviewer,

Below please find a version of the manuscript showing changes over the original.

Best,

Leo 


\title{
Synthetic biology for microbial production of lipid-based biofuels
}

Leo d'Espaux ${ }^{1}$, Daniel Mendez-Perez ${ }^{1}$, Rachel Li ${ }^{1,2}$, and Jay D. Keasling ${ }^{1,2,3}$

\author{
Author Affiliations \\ ${ }^{1}$ Joint BioEnergy Institute, Lawrence Berkeley National Laboratory, Emeryville, California \\ 94608 \\ ${ }^{2}$ Department of Plant and Microbial Biology, University of California, Berkeley, California \\ 94270 \\ ${ }^{3}$ QB3 Institute, Departments of Bioengineering, Chemical and Biomolecular Engineering, \\ University of California, Berkeley, California 94270, United States
}

\begin{abstract}
The risks of maintaining current $\mathrm{CO}_{2}$ emission trends have led to interest in producing biofuels using engineered microbes. Microbial biofuels reduce emissions because $\mathrm{CO}_{2}$ produced by fuel combustion is offset by $\mathrm{CO}_{2}$ captured by growing biomass, which is later used as feedstockfeedstocks for biofuel fermentation. Hydrocarbons found in petroleum fuels share striking similarity with biological lipids. Here we review synthetic metabolic pathways based on fatty acid and isoprenoid metabolism to produce alkanes and other molecules suitable as biofuels. We further discuss engineering strategies to optimize engineeredsynthetic biosynthetic routes, as well as the potential of synthetic biology for sustainable manufacturing.
\end{abstract}

\section{Highlights}

- Biological lipids are naturally energy-dense and several make good biofuels.

- MetabolicWe discuss microbial based biofuels as replacements to petroleum fuels

- We review synthetic pathways to produce thesefor production of fatty acid and isoprenoid biofuelshave beenengineeredin microbial hosts.

- A wide range of tools and methodologies are availabletWe highlight several strategies for improving biofuel production.

- Synthetic biology offers greatmuch untapped potential for sustainable manufacturing.

\section{Introduction}

$\underline{\text { Over the last century, human use of fossil fuels has raised atmospheric } \mathrm{CO}_{2} \text { to levels } 40 \% \text { higher }}$

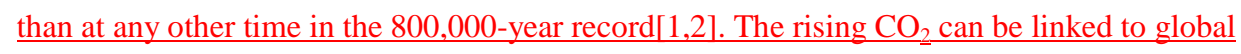


climate change, including more frequent and intense extreme weather events, andrising mean global temperatures. The already-observedtemperature increase of $0.7^{\circ} \mathrm{C}$ is projected to reach $2-8$

${ }^{\circ} \mathrm{C}$ by the end of the century, with potentially catastrophic consequences for our biosphere $[1,3]$.

Over the last century, human activity has released 1 teraton of $\mathrm{CO}_{2}$ into the atmosphere, resulting in levels $33 \%$ higher than any time in the preceding 800,000 years [ 1 ]. The rising $\mathrm{CO}_{z}$ ean be linked to global climate change, including rising temperatures and sea levels. Climate models indicate that global mean temperature today is $0.7^{\circ} \mathrm{C}$ higher than it would be absent human activity [1]. This temperature anomaly is expected to increase to at least $2^{\circ} \mathrm{C}$ and possibly 8 ${ }^{\circ} \mathrm{C}$ by the end of this century. The consequences of such unabated climate change are daunting [2].

Of all anthropogenic $\mathrm{CO}_{2}$ emissions, one quarter originate from theliquid fuel combustion of

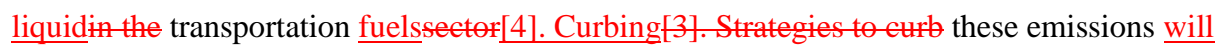
require a multi-faceted approach, including improvedinclude instituting tighter gas mileage and emission standards for vehicle fuel economy and emissions, new vehicles, increasing usage of electric and other alternative-powered vehicles, and usage of biofuels. Biofuels reduce emissions because $\mathrm{CO}_{2}$ produced by fuel combustion is offset by $\mathrm{CO}_{2}$ captured by growing biomass, which is in turn used to produce more fuel(Figure 1). "Drop-in" biofuels that can be used with existing $\underline{\text { vehicles - especially trucks and planes that are impractical to power using current fuel cell }}$ technology — are especially desirable[5]. Stemming from these concerns, several-Many governments including those of the United States, China, and the European Union have instituted mandates for biofuels to constitute an increasing percentage of total transportation fuel usage in the coming years [6][4].

\section{Liquid transportation fuels}

Today, only $2 \%$ of all transportation fuel is bio-based. By far the most prevalent biofuel is ethanol produced by microbial fermentation of sugars blended into gasoline as a volume booster and | oxygenate [7].[5].However, ethanol can only be used as $10 \%$ of the blend due to its low energy density (and other factors). In the United States, most gasoline is already blended at this 10\% ethanol limit.

Besides ethanol, the other predominant biofuel today is fatty acidacyl alkyl ester (FAAE, marketed as biodiesel). FAAE is produced by thermochemical esterification of plant oils with alcohol - typically methanol or ethanol — and used as a diesel substitute. FAAE is chemically 
different from petroleum diesel, and from gasoline. Gasoline is primarily composed of linear and ringed C4-C9 hydrocarbons, diesel and jet fuel C8-21. FAAE, on the other hand, is composed of methyl- or ethyl-esters of linear C16-C22 alkylacyl chains (Figure 2).- The increased oxygen content of FAAE leads to more complete fuel combustion, decreasing particulate and $\mathrm{CO}$ emissions [8].[6]. However, oil crops used as feedstocks for FAAE production have low yields and divertdrain agricultural resources from food crops.

The limitations of first-generation biofuels have generated interest in genetically engineering microorganisms to perform the bioconversion of an abundant and inexpensive feedstock into a biofuel. Here we discuss how various enzymes can be combined to biologically produce molecules suitable as transportation fuels, focusingon lipid-based replacements for diesel and jet fuel produced in the two most well-known microbial hosts, Escherichia coli and Saccharomyces cerevisiae. We also provide an overview of the tools and methodologies of synthetic biology for creating and optimizing biological designs, and outlooks on its potential for future biomanufacturing.

Bio based replacements for diesel and jet fuel are especially desirable since the vehicles they power operate for long lifetimes, and demand high power outputs not easily achievable with eurrent fuel cell technologies. The limitations of oil crop based biodiesel production have generated interest in employing micrøørganisms to perform the biøconversion of a renewable feedstock into a desired biofuel (Figure 1). This presents several potential advantages. First, many organisms are known to grow on a number of abundant and inexpensive feedstocks. Secend, biochemical pathways often exhibit exquisite specificity and complexity, at times producing compounds that are difficult or impossible to produce through synthetic chemistry.

Combining activities into a microbial cell factory has the potential to produce bespoke fuel molecules with improved performance, perhaps cheaply. Lastly, this synthetic biology can, in perturbing and analyzing living systems, offer insights into their inner workings. The ramifications for sustainability, health, and other areas are immense. In this review, we highlight how the tools and methodologies of synthetic biology have been applied to the microbial production of biofuels, with a focus on lipid-based replacements for diesel and jet fuel.

\section{Figure 1. (high-def color image in separate file)}


Carbon cycle for a microbial biofuel. Biofuels reduce emissions because $\mathrm{CO}_{2}$ produced by fuel combustion is offset by $\mathrm{CO}_{2}$ captured by growing biomass, which is in turn used to produce more fuel. With synthetic biology, it may be possible to produce fuel from various sources of carbon and energy. It may also be possible to produce fuels, or other molecules, with improved properties, , or other compounds, using the diverse bioconversions observed in living organisms.

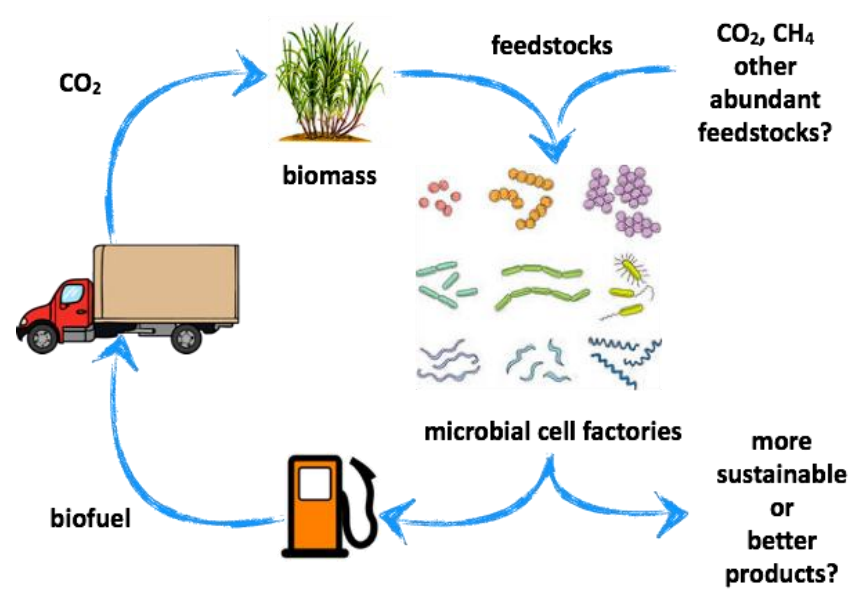

\section{Hydrocarbons and lipids}

The hydrocarbons we use as fuels today sharehave striking similarity withte some of the lipids most organisms use to store energy (Figure 2). LipidsThese compounds are naturally energydense, and many exhibit other properties desirable in a biofuel.making them attractive as biofuels. In fact, early demonstrations of the internal combustion (Diesel) engine used peanut oil as fuel [9].[7]. The triacylglycerides (TAGs) predominant in oils, and other molecules structurally similar to fuels, are produced through the fatty acid biosynthetic pathway. This nearly universally conserved pathway produces some of the major cellular components-e.g., phospholipids and 

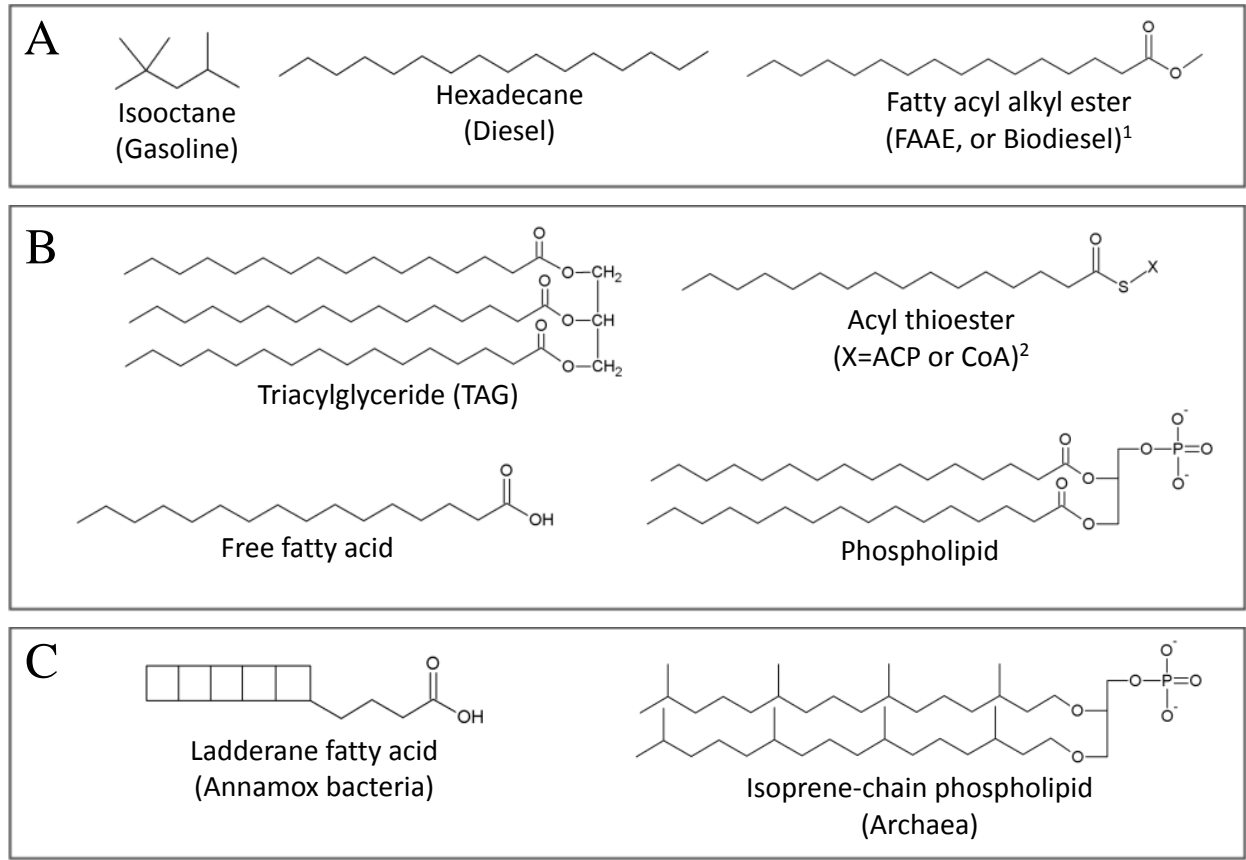

Figure 2 (high-def image in separate file)

Hydrocarbons and lipids. Compounds present in liquid transportation fuels arechemically similartowith compounds produced through fatty acid biosynthesis. (A) Iso-octane is a major component of gasoline, hexadecane of diesel fuel, and FAAE of biodiesel. ${ }^{1}$ FAAE is typically produced using methanol and producing fatty acidacyl methyl ester (FAME). (B) TAGs are produced in many organisms as energy storage molecules, and phospholipids as the main structural components of cellular membranes. Fatty acid biosynthesis produces acyl thioester intermediates that give rise to phospholipids, TAGs, and other molecules. ${ }^{2}$ The acyl chains in these thioesters can be bound to acyl carrier protein (ACP) or CoA, depending on the organism. Generally bacteria employ acyl-ACPs and eukaryotes acyl-

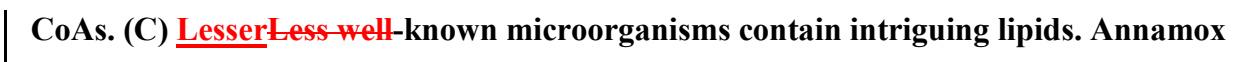
bacteria produce fatty acids containing linearly concatenated cyclobutane rings termed "ladderanes". Archaeal membranes are composed of phospholipids containing isoprenechains linked through ether (rather than ester) linkages.

Fatty acid metabolism 


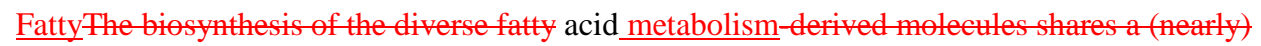
universally conserved pathway. It begins with the carboxylation of acetyl-CoA to malonyl-CoA by acetyl-CoA carboxylase (ACC). Fatty acid synthase (FAS) then condenses one acetyl-CoA starter unit and several malonyl-CoA extender units iteratively to produce a linear acyl chain typically 12-22 carbons long, depending on the organism.- Fatty acids are released as acyl thioesters, bound to either coenzyme A (CoA, in type I FAS) or to acyl carrier protein (ACP, in type II FAS). Most fungi and mammals employ type I FAS, most bacteria type II. Type II FAS is organized as discrete multifunctional polypeptides. By contrast type I FAS is organized as multimeric complexes of one or more polypeptides, each containing multiple enzyme activities.

The length of the product acyl thioesters (acyl CoA or acyl ACP) varies by organism, but is typically $\mathrm{C} 1222$.

After synthesis, acyl thioesters are mainly routed biologically toward membrane phospholipids (containing two acyl chains bound to a glycerol backbone) or energy storage TAGs (containing three). Most organisms can degrade TAGs or other fatty acids through $\beta$-oxidation. Some organisms perform additional bioconversions, such asconsuming alkanes [10], or producing wax esters, polyhydroxyalkanoates, fatty alcohols, orother compounds through variations of this versatile pathway.After synthesis, acyl thioesters are mainly routed biologically toward membrane phospholipids (containing two acyl chains bound to a glycerol backbone) or energy storage TAGs (containing three). Most organisms can degrade TAGs or other fatty acids through $\beta$-oxidation. Some organisms perform additional bioconversions, including consuming alkanes [8], or producing wax esters, polyhydroxyalkanoates, fatty alcohols, and other compounds through this versatile pathway.

\section{Engineered microbial production of fatty-acid derived biofuels}

Genes encoding enzymesThe fact that perform desired chemical conversions can be introduced into an easy-microørganisms employ fatty acid biosynthesis-to-culture-produce high quantities of membrane phospholipids and other molecules has led to interest in diverting the pathway to produce biofuels. A well-known and genetically tractable microbialhost, allowing the such as Escherichia coli or Saccharomyces cerevisiae, can be engineered strain to convert a simple feedstock - e.g., glucose - through fatty acid metabolism into an acyl thioester, then-into a target molecule.biofuel through a heterologous terminal enzyme(s). A number of enzymes have been identified that catalyze the conversion of fatty acids or their intermediates into different products with good fuel properties. 
FAAE - molecularly identical to oil-crop biodiesel — has been produced by heterologously expressing a wax ester synthase (WS) catalyzing the esterification of an acyl thioester with ethanol [11,12]. Several WS enzymes have been shown to catalyze this reaction [13]. FAAE, for example, has been produced by heterologously expressing a wax ester synthase (WS) catalyzing the esterification of an acyl thioester with ethanol $[9,10]$. Several WS enzymes have been shown to catalyze this reaction [11].

$\underline{\text { Alkanes and alkenes - the major constituents of petroleum diesel-have been produced through }}$ various bioengineered routes, such as the reduction of acyl-thioesters (or free fatty acids) into fatty aldehydes followed by decarbonylation [14-16]. Other routes include the decarboxylation of free fatty acids directly into $\alpha$-alkenes by a bacterial cytochrome P450 [16], or polyketide synthase(PKS)-mediated extension-decarboxylation[17].

Similarly, different pathways can be assembled to produce molecules not currently used as fuels, but with likely suitable properties, including fatty alcohols [12,18], methyl ketones [19,20], $\omega$ hydroxy and dicarboxylic acids [21], and other fatty acid-derived products (Figure 3). It should be noted that different tailoring enzymes have different preferences for substrate chain length and terminal moiety, e.g., acyl-ACP, acyl-CoA, or free fatty acids. These can mirror the nature of their host's central FAS pathway - type I produces acyl-CoA, type II acyl-ACP. However, it is possible to introduce a type I FAS pathway into a host that natively employs type II FAS [22], or vice-versa [23]. Additionally, the FAS pathway can be modified to incorporate branched amino acids and produce branched-chain fatty acids[24]. Chain branching lowers freezing point, which is important for fuel performance in high altitudes or cold weather. Alkanes and alkenes the major constituents of petroleum diesel have been produced through various engineered routes. One route is the reduction of acyl thioesters (or free fatty acids) into fatty aldehydes followed by decarbonylation[12 14$]$. A second route to alkanes was demonstrated by Lith et at. in which the bacterial cytochrome P450 Ole $\mathrm{T}_{\text {IE }}$ decarboxylates free fatty acids directly into $\alpha$ allenes [14]. For yet a third route, polyketide synthases (PKSs) have been observed to perform an extensiondecarboxylation reaction on acyl-ACPs involving malonyl-CoA as the extender unit to produce $\alpha$ alkenes [15]. Liu et al. expressed an engineered iterative type IPKS from Streptomyces globisportus, SgeE, and its cognate thioesterase SgeE10, in E. coli to produce polyenes [16]. 
Similarly, different pathways have been shown to produce molecules not currently used as fuels, but with likely suitable properties, including fatty alcohols $[10,17]$, methyl ketones $[18,19], \omega-$ hydroxy and dicarboxylic acids [20], and other fatty acid-derived products (Figure 3).

It should be noted that different tailoring enzymes have different preferences for substrate chain length and terminal moiety, e.g., acyl-ACP, acyl-CoA, or free fatty acids. These can mirror the nature of the central FAS pathway type I produces acyl-CoA, type II acyl-ACP. However, it is possible to introduce a type IFAS pathway into a host that natively employs type IIFAS [21], or vice versa [22]. This can serve as a way to control product chain length, or perhaps to decouple production from endogenous regulation. Additionally, chain branching which lowers the biofuel freezing point to improve cold flow properties_ ean be introduced by incorporating branched amino acids as FAS starter units (rather than acetyl-CoA) [23].

\section{Isoprenoid metabolism}

Branching is a defining feature of isoprenoids, another main class of lipids that produces molecules similar to those found in fuels. Also called terpenoids, these molecules are defined by being formed from 5-carbon isoprene building blocks into thousands of molecules, encompassing $60 \%$ of known natural products[25]. Isoprenoids are better known as plant $\underline{\text { secondary metabolites. However they perform diverse functions in all kingdoms of life. In }}$ archaea, for example, isoprenoids are part of primary metabolism and comprise the hydrophobic chains of cell membranes (Figure 2). Branching is a defining feature of another main class of lipids that produces molecules similar to those found in fuels, the isoprenoids. These molecules are defined by formed from 5 -carbon isoprene building blocks, and make up $60 \%$ of known natural productsincluding sterols, cannabinoids, and several vitamins [24]. Isoprenoids, rather than fatty acids, comprise the hydrophobic chains of archaea cell membranes.

Isoprenoidsare synthesized through one of two pathways: the 1-deoxy-D-xylulose 5-phosphate (DXP) pathway (native to most bacteria) or the mevalonate (MVA) pathway (native to most eukaryotes and archaea). The MVA pathway begins with three acetyl-CoA molecules ${ }_{2}$ (which combine to form mevalonate through) and censists of six enzyme-catalyzed steps.enzymes. The DXP pathway begins with pyruvate and glyceraldehyde-3-phosphate ${ }_{2}$ - which eombine to-form DXP through) and consists of seven stepsenzymes. Both pathways proceed further to formend with the production of the five-carbon building blocks isopentenyl pyrophosphate (IPP) and 
dimethylallyl pyrophosphate (DMAPP). IPP and DMAPPcan beThese $5 \mathrm{C}$ units are then condensed and modified in various waysto produce geranyl pyrophosphate (GPP), farnesyl pyrophosphate (FPP), and geranylgeranyl pyrophosphate (GGPP) by various kinds of terpenetheir respective synthases (TPSs) to form thousands. Further modification (e.g., hydrolysis, cyclization, hydroxylation) creates a wide array of products. C10 and C15 isoprenoids, called respectively: monoterpenes and (C10, derived from GPP), sesquiterpenes, ${ }_{2}(\mathrm{C} 15$, from FPP), and diterpenes (20, from GGPP), as well as those from greater multiples of five carbons. Monoterpenes and sesquiterpenes have appropriate carbon numbers for a liquid biofueluse as diesel grade biofuels.

\section{Engineered microbial production of isoprenoid-acid derived biofuels}

Monoterpenes (C10) are produced by the condensation of IPP and DMAPP into geranyl pyrophosphate (GPP) catalyzed by GPP synthase, and further modified by any number of monoterpene synthases. Synthetic pathways to monoterpenes such as $\alpha$-pinene [26],sabinene [27], limonene [28], and geraniol [29], have been successfully constructed in microbial hosts. Monoterpene production has been engineered by overexpressing GPP synthase (GPPS) and different monoterpene synthase genes. Yang et al. produced $\alpha$-pinene in E. coli by expressing a heterologous $S$. cerevisiae MVA pathway combined with pine GPPS and $\alpha$ pinene synthase genes [25]. Combining GPPS and different monoterpene synthases has led to production of other monoterpenes including sabinene [26], limonene [27], and geraniol [28].

$\underline{\text { Sesquiterpenes (C15) are produced by the condensation of two IPP molecules and one DMAPP }}$ into farnesyl pyrophosphate (FPP) by FPP synthase, and subsequent modification by sesquiterpene synthases. Combining pathways to FPP with various sesquiterpene synthasesin microbial hosts has produced bisabolene [30] and $\alpha$-farnesene [31].

Sesquiterpenes (C15) can be produced by overexpression of FPP synthase (FPPS) and sesquiterpene synthases. In an early example, Peralta Yahya et at. produced bisabolene by combining the MVA pathway, FPPS, and a bisabolene synthase in E. coli [29]. The same pathway was successfully ported to $S$. cerevisiae[29]. Following a similar strategy (of using a heterologous MVA and FPPS in E. coli) Wang et al.employed an $\alpha$-farnesene synthase to produce $\alpha$ farnesene [30].

\section{Figure 3(high-def color image in separate file)}




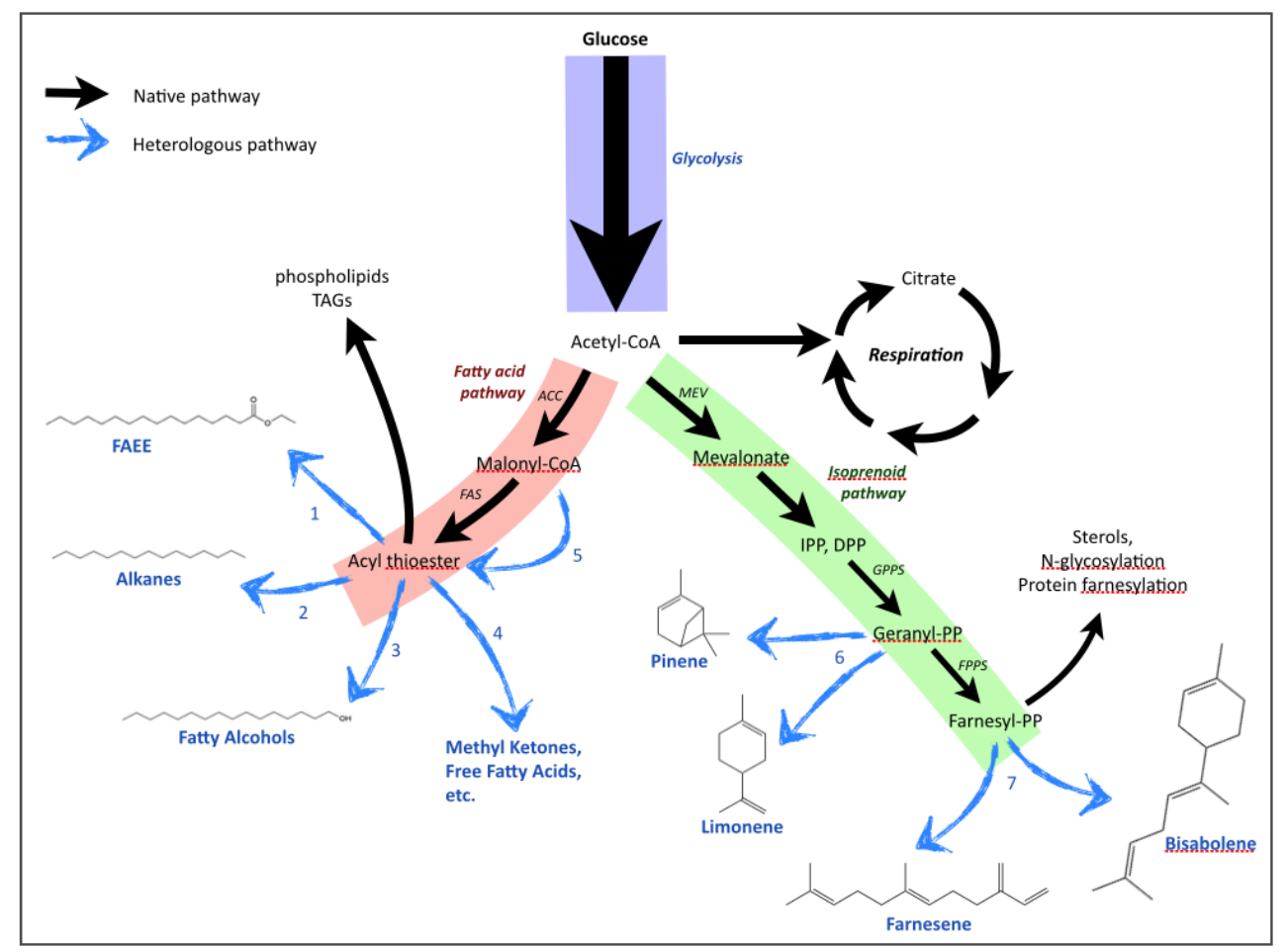

Biosynthetic routes for the production of natural and synthetic fuels from glucose. Fatty acid biosynthesis (pink)naturally produces phospholipids for membrane composition, and

TAGs for energy storage. Isoprenoid biosynthesis (green) naturally produces sterols and other compounds. These pathways can be coopted using heterologous genes to produce a number of biofuel molecules. From acyl thioesters: 1, Esterification with ethanol by wax synthase [11] to produce FAEE; 2, Reduction followed by decarbonylation [14-16], or PKSmediatedextension-decarboxylation [32] to produce alkanes/enes; 3, Reduction either directly [22] or through fatty aldehydes intermediates[18] to produce fatty alcohols; 4 , Other routes to other products $[12,19] ;$, Heterologous FAS pathways [22,23];

6,Monoterpene synthases can modify C10 geranyl-PP to produce pinene, limonene, or other monoterpenes [28,33]; 7,Sesquiterpene synthases can modify C15 Farnesvl-PP to form farnesene, bisabolene, or other sesquiterpenes[30,31]. Unsaturated lipids can be chemically hydrogenated for biofuel production (e.g., farnesene to farnesane). ACC, acetyl-CoA carboxylase; FAS, fatty acid synthase. The isoprenoid pathway shown is the mevalonate (MEV) pathway. Bacteria employ an alternative route, the DXP pathway, not shown for simplicity. Biosynthetic routes for the production of natural and-synthetic fuels from glucese. Fatty acid biosynthesis (pink)naturally produces phospholipids for membrane 
composition, and TAGs for energy storage. Isoprenoid biosynthesis (green) naturally produces-sterols and other compounds. These pathways can be coopted using heterologous genes to produce a number of biofuel molecules. From acyl-thioesters: 1, Esterification-with ethanol by wax synthase [9] to produce FAEE; 2, Reduction followed by decarbonylation [12 14], or PKS-mediatedextension-decarboxylation [15] to produce alkanes/enes; 3, Reduction either directly [21] or through fatty aldehydes intermediates[17] to produce fatty alcohols; 4, Other routes to other products $[10,18]$; 5, Heterologous FAS pathways $[21,22]$; 6,Monoterpene synthases can modify C10 geranyl-PP to produce pinene, limonene, or other monoterpenes [27,31]; 7 , Sesquiterpene symthases can modify C15 Farnesyl-PP to form farnesene, bisabolene, or other sesquiterpenes [29,30]. Unsaturated lipids can be chemically hydrogenated for biofuel production (e.g., farnesene to farnesane). ACC, acetyl-CoA carboxylase; FAS, fatty acid-synthase. The isoprenoid pathway shown is the mevalonate (MEV) pathway. Bacteria employ an alternative route, the DXP pathway, not shown for simplicity.

Alkanes and alkenes the major constituents of petroleum diesel have been produced through various engineered routes. One route is the reduction of acyl thioesters (or free fatty acids) inte fatty aldehydes followed by decarbonylation. The reduction can be catalyzed by a carboxylic acid reductase (CAR, on free fatty acids) [32], an acyl ACP reductase (AAR) [12], or an acyl CoA reductase (ACR) [13]. In E. coli, acyl-ACP (the product of FAS) can be converted to acyl-CoA by the combined activity of "TesA (a cytoplasmic version of the native acyl-ACP thioesterase) and FadD (the native acyl CoA ligase) [10]. A second route to alkanes was demonstrated by Lit et al. in which the bacterial cytochrome $\mathrm{P} 45001 \mathrm{O} \mathrm{T}_{\text {I- }}$-decarboxylates free fatty acids directly into a-alkenes [14]. For yet a third route, polyketide synthases (PKSs) have been observed to perform an extension-decarboxylation reaction on acyl-ACPs involving malonyl-CoA as the extender unit to produce $\alpha$ alkenes [15]. Lit et al. expressed an engineered iterative type IPKS from Streptomyces globisporus, SgeE, and its cognate thioesterase SgcE10, in E. coli to produce polyenes [16].

\section{Metabolic engineeringEngineering strategies for lipid-based biofuelsmierobial}

\section{bioproduction}

Constructing and optimizing an engineered biosynthetic pathway is not a trivial feat. The distribution of molecular fluxes through metabolism depends on many factors, including the thermodynamies of the constituent reactions, kinetics of pathway enzymes including their 
affinity for substrates, or inhibitors and complex multi level regulation. How these factors interact to coordinate metabolism is an active area of research [33]. Yet, several tools and methodologies are available to guide efforts to rewire metabolism.

First, having decided on a pathway to employ, a common tool for improving heterologous gene expression is codon optimization — ostensibly to change gene sequences to match the new host's codon usage, although the exact relationship between codon usage and active expression is poorly understood. Improving an enzyme's activity or changing its substrate preference can also be achieved through directed evolution [34].

Random mutagenesis can also be performed on the whole genome, and combined with highthroughput screening to identify beneficial mutations. There are now an increasing number of computational tools to simulate and optimize metabolic flux distributions, with mixed success [35]. Traditional-approaches include a "pull push block" strategy to maximize metabolic flux toward the product. Blocking consumption of products or intermediates can be achieved by deleting genes catalyzing undesirable reactions [10,36,37]. "Pulling" on a pathway can be achieved by overexpressing terminal enzymes, or providing a sink, which create a thermodynamic driving force for forward flux.

"Pushing" flux involves overcoming bottlenecks that could form along the pathway. For example, carboxylation of acetyl-CoA into malonyl-CoA by ACC is known to be the rate-limiting step of fatty acid biosynthesis in many organisms [38]. The regulation of entry into this energy draining pathway can oceur at various steps.InE ACC ACP. This minim e.g., by expressing a thioesterase [10]. In $S$. Having chosen a set of enzyme activities as a biosynthetic route to a biofuel, achieving good production levels is often challenging and time-consuming. Traditional metabolic engineering often employs a"pull-push-block" approach. "Pulling" on a pathway by overexpressing terminal enzymes or providing an irreversible sink-such as partitioning into a separate phase [12] — can create a thermodynamic driving force for product formation.

"Blocking" consumption of products or intermediates can be achieved by deleting genes catalyzing undesirable reactions $[12,34,35]$. "Pushing" flux involves overcoming bottlenecks that mayform along the pathway. The problems, and solutions, are oftenspecific to the pathway and host organism. 
$\underline{\text { In fatty acid biosynthesis, for example, a common bottleneck is the carboxylation of acetyl-CoA }}$ into malonyl-CoA by ACC [36].eerevisiae, ACC transcription is inhibited by elevated fatty acid levels. Replacing the native ACC promoter with a strong constitutive promoter has led to improved fatty product titers [36]. Another layer of $A C C$ regulation occurs at the posttranslational level, where phosphorylation in response to signals such as glucese depletioninhibits enzyme activity. Mutating the phosphorylation sites in ACC has resulted in increased titers of fatty acid products [39].

In E. coli, ACC activity is inhibited by the product acyl-ACP. This inhibition can be minimized by converting acyl-ACP to other products that do not inhibit ACC-e.g., by expressing a thioesterase [12]. In S. cerevisiae, ACC activity is inhibited post-translationally byphosphorylation in response to signals - such as glucose depletion. Mutating phosphorylation $\underline{\text { sites in ACC has resulted in increased titers of fatty acid products [37]. Another layer of }}$ regulation in yeast is transcriptional inhibition of ACC in response to elevated fatty acid levels. $\underline{\text { Replacing the native ACC promoter with one that is constitutivelyactive has led to improved fatty }}$ product titers [34].

The availability of the central metabolite acetyl-CoA is important not only for fatty acid-derived products, but also isoprenoids produced through the mevalonate pathway, and many other targets. An additional bottleneck for biosynthesis of fatty acid and many other bio products_e.g., isoprenoids produced through the MVA pathway is the availability of cytoplasmic acetyl-CoA. In $S$. cerevisiae this metabolite is provided to different subcellular pools through various biosynthetic routes [40]. The route to cytoplasmic acetyl CoA is energetically draining and suppressed in many conditions. This yeast is known to operate a metabolic switch that favors the formation of ethanol over that of acetate and later acetyl- $\mathrm{CoA}$ in the high-glucose conditions commonly encountered in laboratory and industrial conditions [41]. Strategies to overcome this bottleneck have included expressing heterologous genes or pathways for the provision of acetyl $\operatorname{CoA}[42-45]$.

$\underline{\text { In S. cerevisiae, acetyl-CoA is provided to different subcellular pools through various }}$ biosynthetic routes [38]. The route to cytoplasmic acetyl-CoA is energetically draining and suppressed in the high-glucose conditions typical of laboratory and industrial cultivation(for $\underline{\text { reasons that arestill debated[39,40]). Strategies to overcome this bottleneck have included }}$ expressing heterologous pathways for the provision of this central building block[41-44]. 
A number of other strategies (reviewedelsewhere [45-48])have been used to improve production levels of many biofuel molecules (Table 1). While many improvements in production levels have been realized, there is much room for further optimization to approach maximum theoretical yields.

TABLE 1. Yields of lipid fuels produced in engineered $E$. coli and S. cerevisiae

\begin{tabular}{|c|c|c|c|c|c|c|}
\hline Biofuel & $\begin{array}{c}\underline{\text { Max }} \\
\frac{\text { Theoretical }^{\text {neld }}}{\text { Yield }} \\
\underline{\text { (g/g glucose })}\end{array}$ & Host & $\begin{array}{l}\frac{\text { Titer }}{(g / L)} \\
\text {. }\end{array}$ & 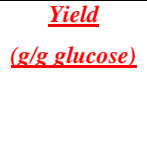 & $\begin{array}{l}\frac{\text { Percent of }}{\text { Max }} \\
\frac{\underline{\text { Theoretical }}}{\text { Yield de }^{e}}\end{array}$ & Reference \\
\hline$F F A$ & \multirow[t]{2}{*}{$\underline{0.37}$} & E. coli & 7.0 & 0.28 & $76 \%$ & [49] \\
\hline$\underline{(C 16)}$ & & S. cerevisiae & 2.2 & $\underline{0.11}$ & $30 \%$ & [35] \\
\hline$\underline{F A E E}$ & \multirow[t]{2}{*}{$\underline{0.36}$} & E. coli & $\underline{1.5}$ & $\underline{0.075}$ & $21 \%$ & [50] \\
\hline$\underline{(C 18)}$ & & S. cerevisiae & $\underline{0.034}$ & $\underline{0.0017}$ & $\leq 1 \%$ & [13] \\
\hline Fatty alcohol & \multirow[t]{2}{*}{$\underline{0.34}$} & E. coli & $3.8^{\mathrm{B}}$ & $\underline{0.13}$ & $38 \%$ & {$[22]$} \\
\hline (C16) & & S. cerevisiae & 1.1 & $\underline{0.055}$ & $16 \%$ & {$[18]$} \\
\hline Alkanes & \multirow[t]{2}{*}{$\underline{0.30}$} & E. coli & $\underline{0.58}$ & $\underline{0.029}$ & $8 \%{ }^{\mathrm{c}}$ & [15] \\
\hline$\underline{(C 15)}$ & & S. cerevisiae & $\underline{0.0037}$ & 0.00019 & $\leq 1 \%$ & [51] \\
\hline Bisabolene & \multirow[t]{2}{*}{$\underline{0.27}$} & E. coli & $\underline{1.1}$ & $\underline{0.055}$ & $20 \%$ & [52] \\
\hline (C15) & & S. cerevisiae & 1.0 & 0.050 & $19 \%$ & [30] \\
\hline
\end{tabular}

Titers and yields of current laboratory-scale demonstrations of selected microbial biofuels produced in $E$. coli and $S$. cerevisiae. In general, experiments were performed using $2 \%$ glucose in shake flask fermentations.

${ }^{\mathrm{A}}$ Maximum theoretical yields are calculated using an in silico optimization algorithm employing a whole genome-scale reconstruction [53,54].

B This example used $3 \%$ glucose rather than $2 \%$.

${ }^{\mathrm{C}}$ This example produced $\mathrm{C} 8$ alkanes, with a different maximum theoretical yield, which is nevertheless accounted for in the percent yield calculation.

Synthetic biology tools and methodologies

Formatted: Font: Bold

Synthetic biology today encompasses an increasing number of tools and methodologies to facilitate strain construction and optimization. Synthesizing, sequencing, and introducing DNA sequences into living cells [55] is cheaper and easier than ever. Codon-optimization, directed evolution [56], screening enzyme libraries, and incorporating non-natural amino acids[57] all provide ways of improving or generating novel enzymatic activities. 
Moving beyond which genes to express (or delete), how to express them - when, where, and at what level — can have significant effects on the growth rate and product titer of engineered strains. It is a defining feature of biological systems that their constituent parts are interconnected-as compared to electrical circuits or chemical engineering unit operations. More fully characterizing and modeling biological systems will reveal principles and design rules for synthetic biology $[52,58]$. These can be implemented using an increasing number of tools to programgene expression: ribosome binding sites (RBSs)[59], promoters[60], trans-acting activators[61], sensors and switches[50,62], enzyme fusions [63], scaffolds [64], localization tags [65], and other genetic "parts". Employing these in ways approaching the complex natural orchestration of metabolism [66] will be necessary for more sophisticated and better performing biological designs. Metabolic bottlenecks can arise due to thermodynamic constraints, and from multi level cellular control. Powerful gene regulatory networks can present obstacles, and perhaps opportmities. In yeast, Feng et al. found several transcription factors which when deleted improved fatty chemical yields [17]. In E. coli, deletion of the gene encoding the transcriptional regulator FadR which regulates fatty acid biosynthesis and degradation depending on the availability of fatty acids has been employed by several groups to improve fatty chemical titers. Bellomonaco et al. instead overexpressed FadR as well as other regulatory genes to achieve a functional reversal of $\beta$ - oxidation producing a number of fatty chemicals from glucose [46]. Zhang et al. created a sensor-regulator system comprising FalR and cognate synthetic promoters which work together to regulate the expression of atfA and fadD (a pathway to produce FAAE) based on levels of fatty acid intermediates [47]. This dynamically responsive pathway produced the highest FAAE titer reported to date (Table 1).

TABHE 1. Yields of lipid fuls produed in engineed $E_{\text {. }}$

\begin{tabular}{|c|c|c|c|c|c|c|}
\hline Biofuel & $\begin{array}{c}\text { Max } \\
\text { Theoretical } \\
\text { Yield }^{4} \\
\text { (g/g glucese) }\end{array}$ & Hest & $\begin{array}{l}\text { Titer } \\
(\mathrm{g} / \mathrm{L})\end{array}$ & $\begin{array}{c}\text { Yield } \\
(\mathrm{g} / \mathrm{g} \text { glucese })\end{array}$ & $\begin{array}{c}\text { Percent of } \\
\text { Max } \\
\text { theoretical } \\
\text { yield }^{e}\end{array}$ & Reference \\
\hline \multirow{2}{*}{$\begin{array}{l}\text { FFA } \\
(C 16)\end{array}$} & \multirow[t]{2}{*}{0.37} & E. coli & 7.0 & 0.28 & $76 \%$ & {$[46]$} \\
\hline & & S. cerevisiae & 2.2 & $\theta .11$ & $30 \%$ & {$[37]$} \\
\hline \multirow{2}{*}{$\begin{array}{r}\text { FAEE } \\
(C 18)\end{array}$} & \multirow[t]{2}{*}{0.36} & E. coli & 1.5 & 0.075 & $21 \%$ & [47] \\
\hline & & S. cerevisiae & 0.034 & $\theta .0017$ & $<1 \%$ & [11] \\
\hline \multirow{2}{*}{$\begin{array}{r}\text { Fatty alcohol } \\
\text { (C16) }\end{array}$} & \multirow[t]{2}{*}{0.34} & E. coli & $3.8^{B}$ & $\theta .13$ & $38 \%$ & {$[21]$} \\
\hline & & S.cerevisiae & 1.1 & 0.055 & $16 \%$ & {$[17]$} \\
\hline
\end{tabular}




\begin{tabular}{||r|c|r|c|c|c|l|}
\hline $\begin{array}{r}\text { Alkanes } \\
\text { (C15) }\end{array}$ & \multirow{2}{*}{0.30} & E. coli & 0.58 & 0.029 & $8 \%$ & {$[13]$} \\
\cline { 3 - 7 } & & S. cerevisiate & 0.0037 & 0.00019 & $<1 \%$ & {$[48]$} \\
\hline $\begin{array}{r}\text { Bisabolene } \\
\text { (C15) }\end{array}$ & \multirow{2}{*}{0.27} & E. coli & 1.1 & 0.055 & $20 \%$ & {$[49]$} \\
\cline { 3 - 7 } & & S. cerevisiat & 1.0 & 0.050 & $19 \%$ & {$[29]$} \\
\hline
\end{tabular}

\section{Titersand yields $\theta$ fetrrent laboratory-sealedemonstrations of selected mierobialbiofuls

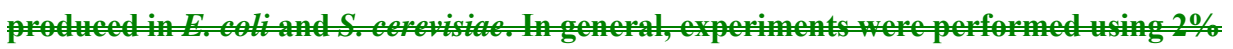 olteos in shake flask fermentations: \\ "Maximum theoretical yields are caleulated using an in silico-optimization-algorithm employing a wholegenome-sede reonstution}

While we have constrained our discussion to S. cerevisiae and E. coli, several other $\underline{\text { microorganisms are already used as hosts for engineered bioproduction [67]. A different host }}$ organism may have a significantly different base metabolism, availability of substrates and cofactors, or compatibility with heterologous genes, which can lead to better pathways. Exploring and developing genetic tools for non-traditional hosts will open possibilities for novel metabolic pathways.

$\lceil 50,51\}$.

${ }^{B}$ This example used $3 \%$ glucese rather than $2 \%$.

${ }^{\mathrm{E}}$ This example produced C8 alkanes, with a different maximum theoretical yield, which is nevertheless accounted for in this value. $\triangle$

\section{Conclusions}

With more powerful synthetic biology tools, the concept of "host" gives way to a fundamentally different synthetic organism. It's worth considering how thedesign objectives differ between a natural organism that evolved to maximize fitness in a given ecological niche, and one synthetically constructed to convert a feedstock into a product. How to realize these radically different objectives is a current aim in synthetic biology. The propensity of organisms to growrather than to necessarily produce a target molecule - can lead to lower product yields. The propensity to mutate - perhaps necessary to adapt to changing environmental conditions - may not be desirable in constant fermentation conditions, and in fact yield to strain instability. Many of these concerns have significant impacts on the viability of microbial bioproduction.

For biofuels, strain performance isparamount. A gallon of petroleum gasoline sells for less than a gallon of water [68]. Techno-economic analysisshows that microbial biofuels provide for $\underline{\text { significant reductions in } \mathrm{CO}_{2}} \underline{\text { emissions over using petroleum fuels [69]. However, these savings, }}$ 
and the economic viability of such bioprocesses, depend largely on biochemical pathway yields and feedstock costs. Bioprocesses that utilize as feedstock cellulosic biomass-agricultural or wood industry by-products, grasses growing on marginal land, etc. - offer maximal $\mathrm{CO}_{2}$ offsets, and don't compete with food production [70]. In the future it may be possible to engineer strains that grow directly on cellulosic biomass, or other abundant and inexpensive substrates, such as methane or $\mathrm{CO}_{2}$. Or it may be possible to produce molecules with better performance, or as yet unimagined uses.As synthetic biology matures, this young technology holds vast potential tosupplant the fossil economy with a sustainable and versatile biomanufacturing platform.

The extent to which biofuls produced from engineered microorganisms replace fossil fuels involves complex cost vs. benefits questions in areas beyond science and engineering. Technoeconomic analysis including the effects of feedstock production shows that biofuels produced from sugarcane or cellulosic biomass by microbial fermentation provide for significant reductions in $\mathrm{CO}_{2}$-emissions over using petroleum fuels [52]. Cellulosic biomass agricultural or wood industry by-products, grasses growing on marginal land, etc. can be broken down into sugars by thermochemical means and then used as fermentation feedstocks. A US Department of Energy report concluded that biomass is abundant and can replace $30 \%$ of transportation fuel by 2030 [53]. Cellulosic bioethanol production is already in commercial development. Other biofuels in industrial production include isobutanol, alkanes, and farnesane.

Limitations yet remain in developing biomanufacturing processes that compete with fossil fuels en cost. A gallon of petroleum gasoline sells for less than a gallon of water [54]. Biofuel strains ean take years develop, and yields are often low. Yet this is more a limitation of our current sophistication than a fundamental one. Many of the engineered pathways discussed in the text employ a handful of promoters and terminators, compared to the thousands natively employed by these host organisms. Utilizing a larger repertoire of natural [55] and synthetic [57]parts, along with better gene editing tools [60], will expand the capabilities of synthetic biological designs.

What will tomorrow's microbial fuel producers do? Will the be $E$. coli, yeast, or something else? Will they grow on unprocessed waste[61]? On methane? $\mathrm{CO}_{2}$ ? And what will they produce? Life in our world has branched into myriad manifestations we've only just begun to catalogue. These designs and their capabilities are encoded using four simple letters. We're just now learning how to write. 


\section{Acknowledgements}

We thank Nicholas Clements, Victor Chubukov, and Maren Wehrs for suggestions while preparing this manuscript.

This work was funded by the Joint BioEnergy Institute (JBEI), which is funded by the U.S Department of Energy, Office of Science, Office of Biological and Environmental Research, under Contract DE-AC02-05CH11231. 


\section{References}

| (Literature highlights are included in the separate "highlights" file)

1. Pachauri RK, Meyer L, Van Ypersele J-P, Brinkman S, Van Kesteren L, Leprince-Ringuet N, Van Boxmeer F: IPCC Climate Change 2014 Synthesis Report [Internet]. 2014.

2. Wood RA, Vellinga M, Thorpe R: Global warming and thermohaline circulation stability. [Internet]. Philos. Trans. A. Math. Phys. Eng. Sci. 2003, 361:1961-74; discussion 1974-5.

3. CO2 Emissions From Fuel Combustion: Highlights (2014 Edition). 2014.

4. Lane J: Biofuels Mandates Around the World 2015 [Internet]. Biofuels Dig. 2015, [no volume].

5. Gomez J, Brasil T, Chan N: An Overview of the Use of Oxygenates in Gasoline. 1998.

6. Liu H, Bi X, Huo M, Lee CFF, Yao M: Soot Emissions of Various Oxygenated Biofuels in Conventional Diesel Combustion and Low-Temperature Combustion Conditions. Energy and Fuels 2012, 26:1900-1911.

7. Diesel R: The Diesel oil-engine. Engineering 1912, 93:395-406.

8. Zengler K, Richnow HH, Rosselló-Mora R, Michaelis W, Widdel F: Methane formation from long-chain alkanes by anaerobic microorganisms. [Internet]. Nature 1999, 401:266-9.

9. Kalscheuer R, Stölting T, Steinbüchel A: Microdiesel: Escherichia coli engineered for fuel production. Microbiology 2006, 152:2529-2536.

10. Steen EJ, Kang Y, Bokinsky G, Hu Z, Schirmer A, McClure A, Del Cardayre SB, Keasling JD: Microbial production of fatty-acid-derived fuels and chemicals from plant biomass. [Internet]. Nature 2010, 463:559-62.

11. Shi S, Valle-Rodríguez JO, Khoomrung S, Siewers V, Nielsen J: Functional expression and characterization of five wax ester synthases in Saccharomyces cerevisiae and their utility for biodiesel production. [Internet]. Biotechnol. Biofuels 2012, 5:7. 
12. Schirmer A, Rude M a, Li X, Popova E, del Cardayre SB: Microbial biosynthesis of alkanes. [Internet]. Science 2010, 329:559-62.

13. Choi YJ, Lee SY: Microbial production of short-chain alkanes [Internet]. Nature 2013, 502:571-4.

14. Liu Y, Wang C, Yan J, Zhang W, Guan W, Lu X, Li S: Hydrogen peroxide-independent production of $\alpha$-alkenes by OleTJE P450 fatty acid decarboxylase.Biotechnol. Biofuels 2014, 7:28.

15. Mendez-Perez D, Begemann MB, Pfleger BF: Modular synthase-encoding gene involved in alpha-olefin biosynthesis in Synechococcus sp. strain pcC 7002. Appl. Environ. Microbiol. 2011, 77:4264-4267.

16. Liu Q, Wu K, Cheng Y, Lu L, Xiao E, Zhang Y, Deng Z, Liu T: Engineering an iterative polyketide pathway in Escherichia coli results in single-form alkene and alkane overproduction. Metab. Eng. 2015, 28:82-90.

17. Feng X, Lian J, Zhao H: Metabolic engineering of Saccharomyces cerevisiae to improve 1-hexadecanol production [Internet]. Metab. Eng. 2014, 27:10-19.

18. Goh E-B, Baidoo EEK, Burd H, Lee TS, Keasling JD, Beller HR: Substantial improvements in methyl ketone production in E. coli and insights on the pathway from in vitro studies [Internet]. Metab. Eng. 2014, 26:67-76.

19. Goh E-B, Baidoo EEK, Keasling JD, Beller HR: Engineering of bacterial methyl ketone synthesis for biofuels. [Internet]. Appl. Environ. Microbiol. 2012, 78:70-80.

20. Clomburg JM, Blankschien MD, Vick JE, Chou A, Kim S, Gonzalez R: Integrated engineering of $\beta$-oxidation reversal and $\omega$-oxidation pathways for the synthesis of medium chain $\omega$-functionalized carboxylic acids [Internet]. Metab. Eng. 2015, 28:202-212.

21. Haushalter RW, Groff D, Deutsch S, The L, Chavkin T a., Brunner SF, Katz L, Keasling JD: Development of an orthogonal fatty acid biosynthesis system in E. coli for oleochemical production [Internet]. Metab. Eng. 2015, 30:1-6. 
22. Fernandez-Moya R, Leber C, Cardenas J, Da Silva NA: Functional replacement of the Saccharomyces cerevisiae fatty acid synthase with a bacterial type II system allows flexible product profiles. [Internet]. Biotechnol. Bioeng. 2015, doi:10.1002/bit.25679.

23. Haushalter RW, Kim W, Chavkin TA, The L, Garber ME, Nhan M, Adams PD, Petzold CJ, Katz L, Keasling JD: Production of anteiso-branched fatty acids in Escherichia coli; next generation biofuels with improved cold-flow properties. [Internet]. Metab. Eng. 2014, 26C:111-118.

24. Firn R: Nature's Chemicals: The Natural Products that Shaped Our World. Oxford University Press; 2010.

25. Yang J, Nie Q, Ren M, Feng H, Jiang X, Zheng Y, Liu M, Zhang H, Xian M: Metabolic engineering of Escherichia coli for the biosynthesis of alpha-pinene. [Internet]. Biotechnol. Biofuels 2013, 6:60.

26. Zhang H, Liu Q, Cao Y, Feng X, Zheng Y, Zou H, Liu H, Yang J, Xian M: Microbial production of sabinene--a new terpene-based precursor of advanced biofuel.

[Internet]. Microb. Cell Fact. 2014, 13:20.

27. Alonso-Gutierrez J, Chan R, Batth TS, Adams PD, Keasling JD, Petzold CJ, Lee TS: Metabolic engineering of Escherichia coli for limonene and perillyl alcohol production. [Internet]. Metab. Eng. 2013, 19:33-41.

28. Zhou J, Wang C, Yoon S-H, Jang H-J, Choi E-S, Kim S-W: Engineering Escherichia coli for selective geraniol production with minimized endogenous dehydrogenation. [Internet]. J. Biotechnol. 2014, 169:42-50.

29. Peralta-Yahya PP, Ouellet M, Chan R, Mukhopadhyay A, Keasling JD, Lee TS: Identification and microbial production of a terpene-based advanced biofuel. [Internet]. Nat. Commun. 2011, 2:483.

30. Wang C, Yoon S-H, Jang H-J, Chung Y-R, Kim J-Y, Choi E-S, Kim S-W: Metabolic engineering of Escherichia coli for $\boldsymbol{\alpha}$-farnesene production. [Internet]. Metab. Eng. 2011, 13:648-55. 
31. Sarria S, Wong B, García Martín H, Keasling JD, Peralta-Yahya P, Martín HG, Keasling JD, Peralta-Yahya P: Microbial synthesis of pinene. [Internet]. ACS Synth. Biol. 2014, 3:466-75.

32. Howard TP, Middelhaufe S, Moore K, Edner C, Kolak DM, Taylor GN, Parker D a, Lee R, Smirnoff N, Aves SJ, et al.: Synthesis of customized petroleum-replica fuel molecules by targeted modification of free fatty acid pools in Escherichia coli.Proc. Natl. Acad. Sci. U. S. A. 2013, 110:7636-41.

33. Chubukov V, Gerosa L, Kochanowski K, Sauer U: Coordination of microbial metabolism. [Internet]. Nat. Rev. Microbiol. 2014, 12:327-40.

34. Korman TP, Sahachartsiri B, Charbonneau DM, Huang GL, Beauregard M, Bowie JU: Dieselzymes: development of a stable and methanol tolerant lipase for biodiesel production by directed evolution. [Internet]. Biotechnol. Biofuels 2013, 6:70.

35. Chowdhury A, Zomorrodi AR, Maranas CD: k-OptForce: integrating kinetics with flux balance analysis for strain design. [Internet]. PLoS Comput. Biol. 2014, 10:e1003487.

36. Runguphan W, Keasling JD: Metabolic Engineering of Saccharomyces cerevisiae for Production of Fatty Acid-Derived Biofuels and Chemicals. [Internet]. Metab. Eng. 2013, doi:10.1016/j.ymben.2013.07.003.

37. Leber C, Polson B, Fernandez-Moya R, Da Silva N a: Overproduction and secretion of free fatty acids through disrupted neutral lipid recycle in Saccharomyces cerevisiae. [Internet]. Metab. Eng. 2014, 28:54-62.

38. Trotter P: The genetics of fatty acid metabolism in Saccharomyces cerevisiae [Internet]. Annu. Rev. Nutr. 2001, [no volume].

39. Shi S, Chen Y, Siewers V: Improving Production of Malonyl Coenzyme A-Derived Metabolites. MBio 2014, doi:10.1128/mBio.01130-14.Editor.

40. Chen Y, Siewers V, Nielsen J: Profiling of cytosolic and peroxisomal acetyl-CoA metabolism in Saccharomyces cerevisiae. [Internet]. PLoS One 2012, 7:e42475. 
41. Van Urk H, Voll WSL, Scheffers WA, Van Dijken JP: Transient-state analysis of metabolic fluxes in Crabtree-positive and crabtree-negative yeasts. Appl. Environ. Microbiol. 1990, 56:281-287.

42. Shiba Y, Paradise EM, Kirby J, Ro D-K, Keasling JD: Engineering of the pyruvate dehydrogenase bypass in Saccharomyces cerevisiae for high-level production of isoprenoids. [Internet]. Metab. Eng. 2007, 9:160-8.

43. Tang X, Feng H, Chen WN: Metabolic engineering for enhanced fatty acids synthesis in Saccharomyces cerevisiae. [Internet]. Metab. Eng. 2013, 16:95-102.

44. Kozak BUB, van Rossum HM, Luttik MMAH, Akeroyd M, Benjamin KR, Wu L, de Vries S, Daran J-M, Pronk JT, van Maris AJA, et al.: Engineering Acetyl Coenzyme A Supply: Functional Expression of a Bacterial Pyruvate Dehydrogenase Complex in the Cytosol of Saccharomyces cerevisiae [Internet]. MBio 2014, 5:e1696-14.

45. Sonderegger M, Schümperli M, Sauer U: Metabolic engineering of a phosphoketolase pathway for pentose catabolism in Saccharomyces cerevisiae. [Internet]. Appl. Environ. Microbiol. 2004, 70:2892-7.

46. Dellomonaco C, Clomburg JM, Miller EN, Gonzalez R: Engineered reversal of the $\boldsymbol{\beta}$ oxidation cycle for the synthesis of fuels and chemicals. [Internet]. Nature 2011, 476:355-9.

47. Zhang F, Carothers JM, Keasling JD: Design of a dynamic sensor-regulator system for production of chemicals and fuels derived from fatty acids. [Internet]. Nat. Biotechnol. 2012, 30:354-9.

48. Binbin C, Lee D-Y, Matthew Wook C: Combinatorial metabolic engineering of Saccharomyces cerevisiae for terminal alkene production. Metab. Eng. 2015, [no volume].

49. Alonso-Gutierrez J, Kim E-M, Batth TS, Cho N, Hu Q, Chan LJG, Petzold CJ, Hillson NJ, Adams PD, Keasling JD, et al.: Principal component analysis of proteomics (PCAP) as a tool to direct metabolic engineering. [Internet]. Metab. Eng. 2015, 28:123-33. 
50. Pfleger BF, Gossing M, Nielsen J: Metabolic engineering strategies for microbial synthesis of oleochemicals [Internet]. Metab. Eng. 2015, 29:1-11.

51. Caspeta L, Buijs $\mathrm{N}$ a. a., Nielsen $\mathrm{J}$ : The role of biofuels in the future energy supply [Internet]. Energy Environ. Sci. 2013, 6:1077.

52. Caspeta L, Nielsen J: Economic and environmental impacts of microbial biodiesel. [Internet]. Nat. Biotechnol. 2013, 31:789-93.

53. Perlack RD, Stokes BJ: U.S. Billion-Ton Update: Biomass Dupply for a Bioenergy and Bioproducts Industry. 2011.

54. Thompson D: Gas Prices Around the World: Cheaper Than Water and $\mathbf{\$ 1 0}$ a Gallon The Atlantic [Internet]. Atl. 2011, [no volume].

55. Lee ME, DeLoache WC, Cervantes B, Dueber JE: A Highly-characterized Yeast Toolkit for Modular, Multi-part Assembly [Internet]. ACS Synth. Biol. 2015, doi:10.1021/sb500366v.

56. Blount B a, Weenink T, Vasylechko S, Ellis T: Rational diversification of a promoter providing fine-tuned expression and orthogonal regulation for synthetic biology. [Internet]. PLoS One 2012, 7:e33279.

57. Li S, Si T, Wang M, Zhao H: Development of a Synthetic Malonyl-CoA Sensor in Saccharomyces cerevisiae for Intracellular Metabolite Monitoring and Genetic Screening. [Internet]. ACS Synth. Biol. 2015, doi:10.1021/acssynbio.5b00069.

58. Bonnet J, Yin P, Ortiz ME, Subsoontorn P, Endy D: Amplifying Genetic Logic Gates [Internet]. Science (80-. ). 2013, 340:599-603.

59. Win MN, Smolke CD: Higher-order cellular information processing with synthetic RNA devices. [Internet]. Science 2008, 322:456-60.

60. DiCarlo JE, Norville JE, Mali P, Rios X, Aach J, Church GM: Genome engineering in Saccharomyces cerevisiae using CRISPR-Cas systems. [Internet]. Nucleic Acids Res. 2013, 41:4336-43. 
61. Leonowicz A, Matuszewska A, Luterek J, Ziegenhagen D, Wojtaś-Wasilewska M, Cho NS, Hofrichter M, Rogalski J: Biodegradation of Lignin by White Rot Fungi [Internet]. Fungal Genet. Biol. 1999, 27:175-185. 